\title{
Cav3.2 calcium channels control NMDA receptor-mediated transmission: a new mechanism for absence epilepsy
}

\author{
Guangfu Wang, ${ }_{1}$ Genrieta Bochorishvili, ${ }^{1}$ Yucai Chen, ${ }^{1}$ Kathryn A. Salvati, ${ }^{1}$ Peng Zhang, ${ }^{1}$ \\ Steve J. Dubel, ${ }^{2}$ Edward Perez-Reyes, ${ }^{1}$ Terrance P. Snutch ${ }^{3,4}$ Ruth L. Stornetta, ${ }^{1}$ \\ Karl Deisseroth, ${ }^{5,6}$ Alev Erisir, ${ }^{7}$ Slobodan M. Todorovic, ${ }^{8,9}$ Jian-Hong Luo, ${ }^{10}$ Jaideep Kapur, ${ }^{11}$ \\ Mark P. Beenhakker, ${ }^{1}$ and J. Julius Zhu ${ }^{1,9}$ \\ ${ }^{1}$ Department of Pharmacology, University of Virginia, Charlottesville, Virginia 22908, USA; ${ }^{2}$ Laboratoire de Génomique \\ Fonctionnelle, Département de Physiologie, Unité Propre de Recherche 2580, Centre National de la Recherche Scientifique, 34396 \\ Montpellier, France; ${ }^{3}$ Michael Smith Laboratories, ${ }^{4}$ Djavad Mowafaghian Centre for Brain Health, University of British Columbia, \\ Vancouver, British Columbia V6T 1Z4, Canada; ${ }^{5}$ Department of Bioengineering, ${ }^{6}$ Howard Hughes Medical Institute, Stanford \\ University, Stanford, California 94305, USA; ${ }^{7}$ Department of Psychology, University of Virginia, Charlottesville, Virginia 22908, \\ $\mathrm{USA}_{;}{ }^{8}$ Department of Anesthesiology, University of Virginia, Charlottesville, Virginia 22908, USA; ${ }^{9}$ Department of Neuroscience, \\ University of Virginia, Charlottesville, Virginia 22908, USA; ${ }^{10}$ Department of Neurobiology, Zhejiang University School \\ of Medicine, Hangzhou, Zhejiang 310058, China; ${ }^{11}$ Department of Neurology, University of Virginia, Charlottesville, Virginia \\ 22908, USA
}

$\mathrm{Ca}_{\mathrm{V}} 3.2 \mathrm{~T}$-type calcium channels, encoded by $C A C N A 1 H$, are expressed throughout the brain, yet their general function remains unclear. We discovered that $\mathrm{Ca}_{\mathrm{V}} 3.2$ channels control NMDA-sensitive glutamatergic receptor (NMDA-R)-mediated transmission and subsequent NMDA-R-dependent plasticity of AMPA-R-mediated transmission at rat central synapses. Interestingly, functional $\mathrm{Ca}_{\mathrm{V}} 3.2$ channels primarily incorporate into synapses, replace existing $\mathrm{Ca}_{\mathrm{v}} 3.2$ channels, and can induce local calcium influx to control NMDA transmission strength in an activitydependent manner. Moreover, human childhood absence epilepsy (CAE)-linked hCa 3.2(C456S) mutant channels have a higher channel open probability, induce more calcium influx, and enhance glutamatergic transmission. Remarkably, cortical expression of $\mathrm{hCa}_{\mathrm{v}} 3.2(\mathrm{C} 456 \mathrm{~S})$ channels in rats induces 2- to 4-Hz spike and wave discharges and absence-like epilepsy characteristic of CAE patients, which can be suppressed by AMPA-R and NMDA-R antagonists but not $T$-type calcium channel antagonists. These results reveal an unexpected role of $\mathrm{Ca}_{\mathrm{V}} 3.2$ channels in regulating NMDA-R-mediated transmission and a novel epileptogenic mechanism for human CAE.

[Keywords: Cav3.2 channels; synapses; NMDA transmission; childhood absence epilepsy]

Supplemental material is available for this article.

Received February 22, 2015; revised version accepted June 12, 2015.

Low-threshold voltage-gated T-type $\mathrm{Ca}_{\mathrm{V}} 3.1, \mathrm{Ca}_{\mathrm{V}} 3.2$, and Cav3.3 calcium channels, encoded by genes CACNA1G, $C A C N A 1 H$, and CACNA1I, respectively, are widely expressed in various types of neurons throughout the brain (Catterall 2011; Cheong and Shin 2013; Simms and Zamponi 2014). T-type calcium channels activate near the resting membrane potential (RMP). Therefore, it is generally believed that these channels can promote the synchronization of sleep rhythms and absence seizures by modulating membrane properties with low-threshold calcium spikes and calcium-dependent potassium currents. This notion is supported by the recent genetic knockout experiments that demonstrated $\mathrm{Ca}_{\mathrm{V}} 3.1$ and

Corresponding author: jizhu@virginia.edu Article is online at http://www.genesdev.org/cgi/doi/10.1101/gad.260869. 115 .
$\mathrm{Ca}_{\mathrm{V}} 3.3$ to be indispensable for the generation of lowthreshold calcium spikes (Kim et al. 2001; Astori et al. 2011; Lee et al. 2014a). However, the genetic deletion of $\mathrm{Ca}_{\mathrm{v}} 3.1$ and $\mathrm{Ca}_{\mathrm{v}} 3.3$ failed to prevent absence epilepsy in the knockout mice, raising the question of whether these calcium channels are essential for absence seizures. In contrast, the primary function of $\mathrm{Ca}_{\mathrm{V}} 3.2$ channels remains elusive. Interestingly, genetic studies have linked a large number of gain-of-function mutations on the $C A C$ $N A 1 H$ gene, but no confirmed mutation on the $C A C$ NA1G and CACNA1I genes, with human childhood

(C) 2015 Wang et al. This article is distributed exclusively by Cold Spring Harbor Laboratory Press for the first six months after the full-issue publication date (see http://genesdev.cshlp.org/site/misc/terms.xhtml). After six months, it is available under a Creative Commons License (Attribution-NonCommercial 4.0 International), as described at http:// creativecommons.org/licenses/by-nc/4.0/. 
absence epilepsy (CAE) (Chen et al. 2003; Liang et al. 2006; Heron et al. 2007), which is the most common form of pediatric epilepsy (Snead 1995; Tenney and Glauser 2013). More perplexingly, $\sim 50 \%$ of CAE patients did not respond to ethosuximide, a T-type calcium channel antagonist and first-line drug used to treat CAE (Coulter et al. 1989; Huguenard and Prince 1994), and the majority of the nonresponsive patients carry $\mathrm{Ca}_{\mathrm{V}} 3.2$ channel mutations (Glauser et al. 2010). These findings establish the functional significance of $\mathrm{Ca}_{\mathrm{V}} 3.2$ channels but raise the fundamental questions of what the primary function of $\mathrm{Ca}_{\mathrm{v}} 3.2$ channels is and how CAE-linked $\mathrm{Ca}_{\mathrm{v}} 3.2$ mutations may be epileptogenic.

At central synapses, NMDA transmission plays a decisive role in controlling AMPA transmission strength (Kessels and Malinow 2009; Stornetta and Zhu 2011; Huganir and Nicoll 2013). It is also clear that NMDA transmission strength itself is regulated at synapses, albeit the detailed mechanisms and dynamics of this regulation are much less explored (Lau and Zukin 2007; Hunt and Castillo 2012; Paoletti et al. 2013). Since synaptic NMDA transmission is central to fundamental cognitive functions, including sensory perception and behavior adaption, it is not surprising to see that dysregulation of NMDA transmission can lead to various neurological, mental, and psychiatric disorders, including addiction, Alzheimer's disease, autism, depression, pathological pain, and schizophrenia (Lau and Zukin 2007; Russo et al. 2010; Hunt and Castillo 2012; Paoletti et al. 2013; Monteggia and Zarate 2015). However, what controls NMDA transmission strength remains unknown.

We report here an investigation of regulation and function of $\mathrm{Ca}_{\mathrm{V}} 3.2$ channels in multiple distinct types of rat central neurons in intact circuits and intact brains. Using simultaneous multiple patch clamp recordings and/or multiple two-photon imaging techniques (Wang et al. 2015), we found that, in sharp contrast to the other Ttype calcium channels (i.e., $\mathrm{Ca}_{\mathrm{v}} 3.1$ and $\mathrm{Ca}_{\mathrm{v}} 3.3$ channels), Cav3.2 channels did not contribute to either modulation of membrane properties or production of lowthreshold calcium spikes in central neurons. Instead, functional $\mathrm{Ca}_{\mathrm{v}} 3.2$ channels primarily incorporated into synapses by replacing existing synaptic $\mathrm{Ca}_{\mathrm{v}} 3.2$ channels and served to control the strength of NMDA transmission. This Cav3.2 channel-dependent regulation of NMDA transmission required synaptic activity, activation of $\mathrm{Ca}_{\mathrm{v}} 3.2$ channels, and calcium influx. Consistent with these findings, expression of human CAE-linked mutant $\mathrm{hCa}$ 3 $3.2(\mathrm{C} 456 \mathrm{~S})$ channels in rats resulted in replacement of endogenous $\mathrm{Ca}_{\mathrm{V}} 3.2$ channels with higher open probability mutant channels that led to 2 - to $4-\mathrm{Hz}$ spike and wave discharges (SWDs) and absence-like epilepsy characteristic of CAE patients. The SWDs and absence-like epilepsy were suppressed by AMPA receptor (AMPA-R) and NMDA-R antagonists but not T-type calcium channel antagonists. These results reveal a surprising role of $\mathrm{Ca}_{\mathrm{v}} 3.2$ channels in regulation of synaptic NMDA transmission strength and establish the first genetic model for CAE patients carrying $\mathrm{Ca}_{\mathrm{V}} 3.2$ channel mutations.

\section{Results \\ $C a_{V} 3.2$ channels potentiate glutamatergic transmission}

We set out to determine the functional role of $\mathrm{Ca}_{\mathrm{v}} 3.2$ channels on synaptic and intrinsic membrane properties of CA1 pyramidal neurons in the hippocampus, layer 5 (L5) pyramidal neurons in the cortex, and GABAergic neurons in the thalamic reticular nucleus (TRN), all structures expressing relatively high levels of $\mathrm{Ca}_{\mathrm{v}} 3.2$ channels (Talley et al. 1999). We first made acute viral expression of human wild-type and mutant $\mathrm{Ca}_{\mathrm{v}} 3.2$ constructs $\left(\mathrm{hCa}_{\mathrm{v}} 3.2\right)$ and rat $\mathrm{Ca}_{\mathrm{v}} 3.2 \mathrm{C}$ terminus $\left(\mathrm{Ca}_{\mathrm{v}} 3.2\right)$, all tagged with fluorescence proteins, in CA1 neurons of cultured rat hippocampal slices (Fig. 1A; see the Materials and Methods). Electrophysiological recordings were then obtained simultaneously and/or sequentially from multiple nearby neurons expressing wild-type hCa $3.2(\mathrm{WT})$-CFP, mutant hCa $3.2(\mathrm{C} 456 \mathrm{~S})$-GFP, C-terminal Cav3.2ct-RFP, mOrange alone, and control nonexpressing neurons. Afferent fibers were stimulated, and excitatory postsynaptic currents (EPSCs) were recorded. CA1 neurons expressing wild-type hCav3.2(WT)-CFP had the same AMPA-Rmediated and NMDA-R-mediated synaptic responses compared with nearby control nonexpressing neurons (Fig. 1B). In contrast, CA1 neurons expressing hCa 3.2 (C456S)-GFP, a typical CAE-linked gain-of-function Cav3.2 mutant (Chen et al. 2003; Vitko et al. 2005; Chioza et al. 2006), had enhanced AMPA and NMDA responses compared with nearby control nonexpressing neurons (Fig. 1B). These results suggest that expression of gain-offunction, but not wild-type, $\mathrm{Ca}_{\mathrm{v}} 3.2$ channels enhances glutamatergic synaptic transmission. $\mathrm{Ca}_{\mathrm{v}} 3.1, \mathrm{Ca}_{\mathrm{v}} 3.2$, and Cav3.3 T-type calcium channels have substantially less sequence homology in their $\mathrm{C}$ termini, which may confer differential membrane trafficking and/or subcellular compartmental anchoring of the three calcium channel types (McRory et al. 2001). Therefore, we hypothesized that overexpression of a free $\mathrm{Ca}_{\mathrm{v}} 3.2 \mathrm{C}$ terminus peptide would produce a dominant-negative blockade of endogenous $\mathrm{Ca}_{\mathrm{v}} 3.2$ channel function. Indeed, CA1 neurons expressing $\mathrm{Ca}_{\mathrm{v}} 3.2 \mathrm{ct}-\mathrm{RFP}$ had reduced AMPA and NMDA responses compared with nearby nonexpressing neurons (Fig. 1B). To verify that $\mathrm{Ca}_{\mathrm{v}} 3.2 \mathrm{ct}$ specifically blocks the function of $\mathrm{Ca}_{\mathrm{v}} 3.2$ channels, we repeated the experiments in hippocampal cultured slices prepared from wild-type and $\mathrm{Ca}_{\mathrm{v}} 3.2$ knockout mice (Supplemental Fig. S1). As expected, wild-type CA1 neurons expressing Cav3.2ct-GFP had reduced AMPA and NMDA responses. In contrast, $\mathrm{Ca}_{\mathrm{v}} 3.2$ knockout CA1 neurons expressing Cav $3.2 \mathrm{ct}$-GFP had the same AMPA and NMDA responses compared with nearby nonexpressing neurons, suggesting a selective occlusion of the Cav 3 .2ct-GFP-mediated depressive effect on synaptic transmission by genetic knockout of $\mathrm{Ca}_{\mathrm{v}} 3.2$ channels. As a control, CA1 neurons expressing mOrange alone had the same AMPA and NMDA responses compared with nearby control nonexpressing neurons (Fig. 1B). We also found that CA1 neurons expressing hCav3.2(WT)-GFP, hCa 3.2 (C456S)-GFP, and Cav3.2ctGFP had the same RMP, input resistance, membrane 
A

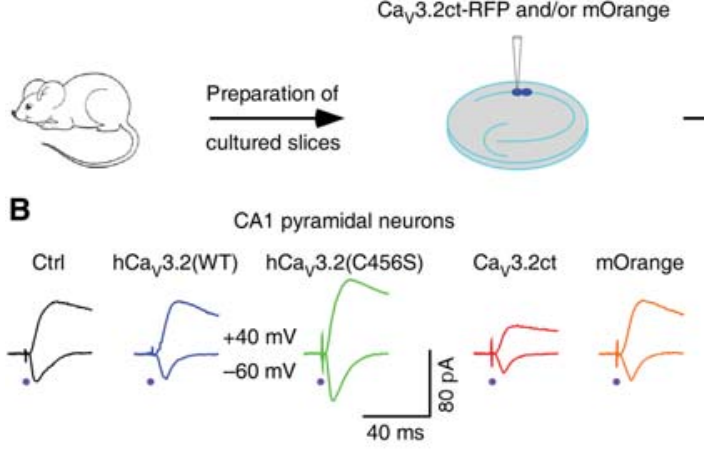

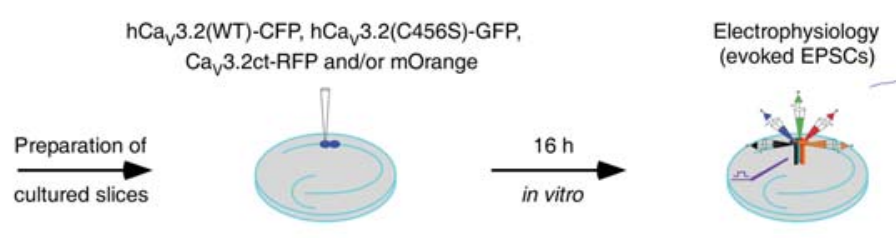
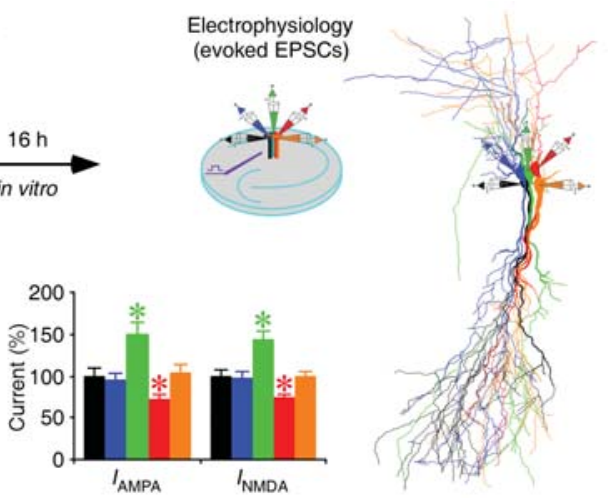
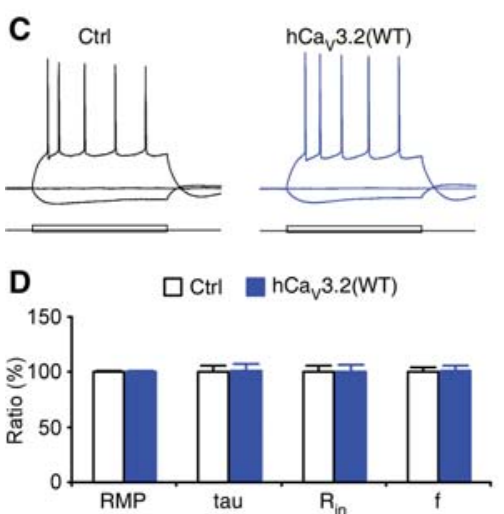
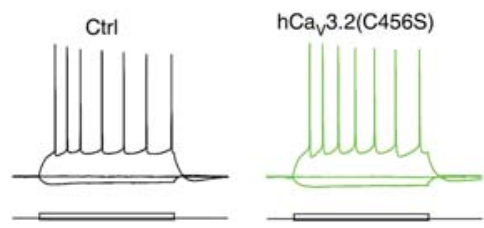

$\square \mathrm{Ctrl} \quad \mathrm{hCa} 3.2(\mathrm{C} 456 \mathrm{~S})$

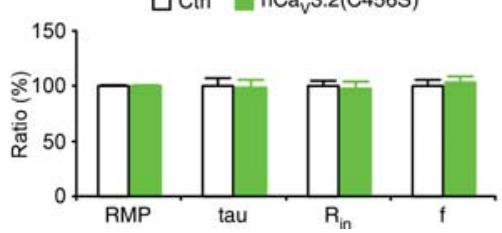

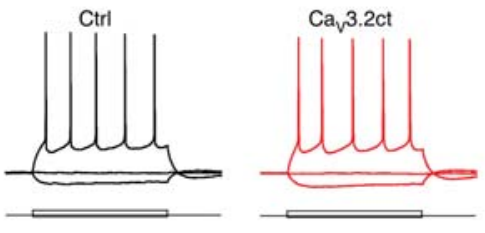

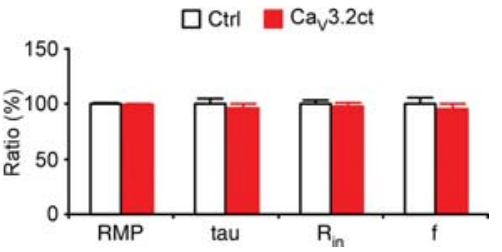

Figure 1. Endogenous $\mathrm{Ca}_{\mathrm{V}} 3.2$ channels control glutamatergic synaptic transmission. (A) Schematic drawing of in vitro experimental design. The reconstruction shows simultaneous whole-cell recordings from neighboring control nonexpressing (black), hCa $3.2(\mathrm{WT})$ CFP-expressing (blue), hCav3.2(C456S)-GFP-expressing (green), Cav3.2ct-RFP-expressing (red), and mOrange-expressing (orange) CA1 neurons in rat hippocampal slices. $(B)$ Evoked AMPA-R-mediated $(-60 \mathrm{mV})$ and NMDA-R-mediated $(+40 \mathrm{mV})$ responses recorded from neighboring control nonexpressing (Ctrl), hCav3.2(WT)-CFP-expressing, hCa 3 .2(C456S)-GFP-expressing, Cav3.2ct-RFP-expressing and mOrange-expressing CA1 neurons cultured in normal medium. Values for AMPA responses in rat CA1 neurons expressing hCa 3.2 (WT)-CFP $(-26.2 \mathrm{pA} \pm 2.3 \mathrm{pA}, n=19$ from 17 animals, $Z=-0.825, P=0.41)$, hCav3.2(C456S)-GFP $(-41.7 \mathrm{pA} \pm 3.6 \mathrm{pA}, n=19$ from 17 animals, $Z=3.421, P<0.005)$, Cav3.2ct-RFP $(-19.9 \mathrm{pA} \pm 1.9 \mathrm{pA}, n=19$ from 17 animals, $Z=-3.419, P<0.005)$, and $\mathrm{mOrange}$ alone $(-28.8 \mathrm{pA}$ $\pm 2.6 \mathrm{pA}, n=19$ from 17 animals, $Z=0.604, P=0.55)$ compared with those in neighboring control nonexpressing CA1 neurons $(-27.7 \mathrm{pA} \pm$ $2.4 \mathrm{pA}, n=19$ from 17 animals). Values for NMDA responses in rat CA1 neurons expressing hCa $3.2(\mathrm{WT})-\mathrm{CFP}(57.3 \mathrm{pA} \pm 4.4 \mathrm{pA}, n=19$ from 17 animals, $Z=-0.684, P=0.49)$, hCa $3.2(C 456 S)$-GFP $(84.1 \mathrm{pA} \pm 6.2 \mathrm{pA}, n=19$ from 17 animals, $Z=3.582, P<0.0005)$, Ca $3.2 \mathrm{ct}-$ $\operatorname{RFP}(43.5 \mathrm{pA} \pm 3.1 \mathrm{pA}, n=19$ from 17 animals, $Z=-2.978, P<0.005)$, and mOrange alone $(58.3 \mathrm{pA} \pm 4.2 \mathrm{pA}, n=19$ from 17 animals, $Z=-0.080, P=0.94)$ compared with those in neighboring control nonexpressing CA1 neurons (59.0 pA $\pm 4.2 \mathrm{pA}, n=19$ from 17 animals). AMPA-R-mediated and NMDA-R-mediated current amplitudes and standard errors were normalized to average values from control cells. Asterisks indicate $P<0.05$ (Wilcoxon tests). (C) Evoked responses to step depolarizing and hyperpolarizing pulses recorded from neighboring control nonexpressing (Ctrl) and hCaC3.2(WT)-GFP-expressing, hCa 3.2 (C456S)-GFP-expressing, or Ca 3.2 ct-GFP-expressing rat CAl neurons held at $-60 \mathrm{mV}$. (D) Values for RMPs (Ctrl: $-60.7 \mathrm{mV} \pm 0.6 \mathrm{mV}$; wild type: $-60.7 \mathrm{mV} \pm 0.5 \mathrm{mV} ; n=33$ from 14 animals, $Z=0.115, P=0.91$ ), time constants (Ctrl: $38.6 \mathrm{msec} \pm 2.2 \mathrm{msec}$; wild type: $39.1 \mathrm{msec} \pm 2.3 \mathrm{msec} ; n=33$ from 14 animals, $Z=0.241, P=0.81$ ), input resistance (Ctrl: $264.3 \mathrm{M} \Omega \pm 14.5 \mathrm{M} \Omega$; wild type: $265.1 \mathrm{M} \Omega \pm 15.9 \mathrm{M} \Omega ; n=33$ from 14 animals, $Z=-0.545, P=0.59$ ), and average spike frequency (Ctrl: $11.1 \mathrm{~Hz} \pm 0.4 \mathrm{~Hz}$; wild type: $11.2 \mathrm{~Hz} \pm 0.5 \mathrm{~Hz} ; n=33$ from 14 animals, $Z=0.241 P=0.81$ ) in neighboring nonexpressing (Ctrl) and hCa 3.2 (WT)-GFP-expressing CAl neurons; for RMPs (Ctrl: $-60.5 \mathrm{mV} \pm 0.7 \mathrm{mV}$; C456S: $-60.4 \pm 0.7 \mathrm{mV} ; n=24$ from 12 animals, $Z=0.168, P=0.87$ ), time constants (Ctrl: $34.4 \mathrm{msec} \pm 2.6 \mathrm{msec}$; C456S: $34.0 \mathrm{msec} \pm 2.4 \mathrm{msec} ; n=24$ from 12 animals, $Z=0.029, P=0.98$ ), input resistance (Ctrl: 246.8 M $\Omega \pm 13.0 \mathrm{M} \Omega$; C456S: 241.3 $\mathrm{M} \Omega \pm 16.3 \mathrm{M} \Omega ; n=24$ from 12 animals, $Z=-0.657, P=0.51$ ), and average spike frequency (Ctrl: $10.6 \mathrm{~Hz} \pm 0.6 \mathrm{~Hz}$; C456S: $11.0 \mathrm{~Hz} \pm 0.6 \mathrm{~Hz} ; n=24$ from 12 animals, $Z=0.343, P=0.73$ ) in neighboring nonexpressing (Ctrl) and $\mathrm{hCa}_{\mathrm{V}} 3.2$ (C456S)-GFP-expressing CA1 neurons; and for RMPs (Ctrl: $-62.4 \mathrm{mV} \pm 0.7 \mathrm{mV}$; Ca $3.2 \mathrm{ct}:-62.1 \mathrm{mV} \pm 0.7 \mathrm{mV}$; $n=29$ from 10 animals, $Z=0.538, P=0.59$ ), time constants (Ctrl: $38.7 \mathrm{msec} \pm 1.8 \mathrm{msec}$; Cav3.2ct: $37.3 \mathrm{msec} \pm 1.5 \mathrm{msec} ; n=29$ from 12 animals, $Z=-0.832$, $P=0.41$ ), input resistance (Ctrl: $283.5 \mathrm{M} \Omega \pm 10.0 \mathrm{M} \Omega ; \mathrm{Ca}_{\mathrm{v}} 3.2 \mathrm{ct}: 276.8 \mathrm{M} \Omega \pm 10.2 \mathrm{M} \Omega ; n=29$ from 12 animals, $Z=-0.789, P=0.43$ ), and average spike frequency (Ctrl: $11.7 \mathrm{~Hz} \pm 0.6 \mathrm{~Hz} ; \mathrm{Ca}_{\mathrm{v}} 3.2 \mathrm{ct}: 11.2 \mathrm{~Hz} \pm 0.5 \mathrm{~Hz} ; n=29$ from 12 animals, $Z=-0.400, P=0.69$ ) in neighboring nonexpressing (Ctrl) and $\mathrm{Ca}_{\mathrm{V}} 3$.2ct-GFP-expressing CA1 neurons.

time constant, and average spiking frequency compared with nearby nonexpressing neurons (Fig. 1C,D; Supplemental Fig. S2), suggesting that expression of these $\mathrm{Ca}_{\mathrm{V}} 3.2$ constructs had no effect on basic membrane properties in CA1 neurons in cultured slices. In addition, expression of hCa $3.2(\mathrm{WT})$-GFP, hCav3.2(C456S)-GFP, and Cav3.2ct- 
GFP had no effect on GABAergic responses and paired pulse facilitation of AMPA responses in CA1 neurons in cultured slices (Supplemental Fig. S3). Together, these results suggest that endogenous $\mathrm{Ca}_{\mathrm{v}} 3.2$ channels contribute to a tonic potentiation of glutamatergic transmission.

\section{$C a_{V} 3.2$ channels regulate glutamatergic transmission at various synapses}

To examine whether expression of $\mathrm{Ca}_{\mathrm{V}} 3.2$ channels affect synaptic transmission in intact brains, we virally expressed hCa $3.2(\mathrm{WT})$-GFP, hCa $3.2(\mathrm{C} 456 \mathrm{~S})-\mathrm{GFP}$, or $\mathrm{Ca}_{\mathrm{V}} 3.2 \mathrm{ct}-\mathrm{GFP}$ in L5 pyramidal neurons and TRN neurons in vivo for $\sim 18 \mathrm{~h}$ and then measured the effects on the synaptic and intrinsic responses of these neurons in acutely prepared slices (Fig. 2A). Compared with the nearby control nonexpressing neurons, L5 pyramidal neurons expressing hCa $3.2(\mathrm{C} 456 \mathrm{~S})$-GFP had enhanced AMPA and NMDA responses, whereas L5 pyramidal neurons expressing $\mathrm{Ca}_{\mathrm{V}} 3.2 \mathrm{ct}-\mathrm{GFP}$ had reduced AMPA and NMDA responses (Fig. 2B,C). Expression of hCa 3 3.2(WT)-GFP in L5 pyramidal neurons had no effect on AMPA and NMDA responses (Fig. 2C). Similar to L5 pyramidal neurons, compared with the nearby nonexpressing neurons, TRN neurons expressing hCa $3.2(\mathrm{C} 456 \mathrm{~S})-\mathrm{GFP}$ had enhanced AMPA and NMDA responses, whereas TRN neurons expressing $\mathrm{Ca}_{\mathrm{v}} 3.2 \mathrm{ct}-\mathrm{GFP}$ had reduced AMPA and NMDA responses (Fig. 2D,E). Expression of hCav3.2(WT)-GFP in TRN neurons had no effect on AMPA and NMDA responses (Fig. 2E). L5 pyramidal neurons expressing hCa 3 3.2(WT)GFP, hCa $3.2(\mathrm{C} 456 \mathrm{~S})$-GFP, or $\mathrm{Ca}_{\mathrm{V}} 3.2 \mathrm{ct}$-GFP in vivo for $\sim 18 \mathrm{~h}$ had the same membrane properties, including $\mathrm{RMP}$, input resistance, membrane time constant, and average spiking frequency, compared with nearby nonexpressing neurons (Supplemental Fig. S4). Similarly, expression of hCa $3.2(\mathrm{WT})$-GFP, hCa $3.2(\mathrm{C} 456 \mathrm{~S})$-GFP, or $\mathrm{Ca}_{\mathrm{v}} 3.2 \mathrm{ct}$ GFP in TRN neurons in vivo for $\sim 18 \mathrm{~h}$ had no significant effect on the basic membrane properties, including RMP, input resistance, membrane time constant, burst firing, and average spiking frequency (Supplemental Fig. S5). Together, the results suggest that $\mathrm{Ca}_{\mathrm{V}} 3.2$ channels regulate glutamatergic transmission in central neurons.

TRN neurons receive glutamatergic synaptic input from both thalamic and cortical afferent fibers. To determine whether $\mathrm{Ca}_{\mathrm{V}} 3.2$ channels enhance AMPA and NMDA responses at thalamic and/or cortical synapses, we simultaneously expressed mCherry-tagged channelrhodopsin-2 (ChR2-mCherry) in the thalamic ventrobasal nucleus (VB) or barrel cortex and hCav3.2-GFP or $\mathrm{Ca}_{\mathrm{v}} 3.2 \mathrm{ct}-\mathrm{GFP}$ in the TRN in vivo (Fig. 2A). Neurons expressing ChR2-mCherry were confined within the VB and barrel cortex after viral delivery in these areas, respectively (Supplemental Fig. S6). After $\sim 18$ h expression of ChR2-mCherry in the VB, we optogenetically activated the thalamic ChR2-mCherry-expressing terminals in the TRN and recorded ensuing EPSCs from TRN neurons in acutely prepared slices. In response to optogenetic stimulation of the thalamic terminals, TRN neurons expressing hCav3.2(C456S)-GFP had enhanced optogenetically evoked AMPA and NMDA responses, while TRN neurons expressing $\mathrm{Ca}_{\mathrm{V}} 3.2 \mathrm{ct}-\mathrm{GFP}$ had reduced optogenetically evoked AMPA and NMDA responses (Fig. 2F,G). Similarly, after $\sim 72 \mathrm{~h}$ of expression of ChR2-mCherry in the barrel cortex, we optogenetically activated the cortical ChR2-mCherry-expressing terminals in the TRN and recorded evoked EPSCs from TRN neurons in vitro. In response to optogenetic stimulation of the cortical terminals, TRN neurons expressing hCav3.2(C456S)-GFP had enhanced optogenetically evoked AMPA and NMDA responses, while TRN neurons expressing Cav3.2ct-GFP had reduced optogenetically evoked AMPA and NMDA responses (Fig. 2F,G). These results indicate that $\mathrm{Ca}_{\mathrm{V}} 3.2$ channels regulate AMPA and NMDA responses at both the thalamic and cortical synapses of TRN neurons. To independently support these findings, we quantified the distribution of AMPA-Rs and NMDA-Rs at thalamic synapses and cortical synapses of the TRN using pre-embedding immunogold labeling. In the TRN, excitatory afferent inputs originating from the thalamus and cortex form the characteristic L terminals and D terminals, respectively, and could thus be unambiguously identified (Ohara 1988). Expression of $\mathrm{hCa}_{\mathrm{v}} 3.2(\mathrm{C} 456 \mathrm{~S})$ increased, whereas expression of $\mathrm{Ca}_{\mathrm{v}} 3.2 \mathrm{ct}$ decreased, the amount of GluA2/3-immunoreactive silver-gold particles in the postsynaptic density (PSD) of the thalamic and cortical synapses in the TRN (Fig. 3A,B). Similarly, expression of $\mathrm{hCa}_{\mathrm{V}} 3.2(\mathrm{C} 456 \mathrm{~S})$ increased, whereas expression of $\mathrm{Ca}_{\mathrm{v}} 3.2 \mathrm{ct}$ decreased, the amount of GluN1-immunoreactive silver-gold particles in the PSD of the thalamic and cortical synapses in the TRN (Fig. 3C,D). These results suggest that $\mathrm{Ca}_{\mathrm{v}} 3.2$ channels function to regulate synaptic incorporation of AMPA-Rs and NMDA-Rs. As a control, expression of $\mathrm{hCa}_{\mathrm{v}} 3.2(\mathrm{WT})$ had no effect on the amounts of GluA2/3- and GluN1-immunoreactive silver-gold particles in the PSD of the thalamic and cortical synapses in the TRN (Fig. 3). Collectively, the electrophysiological, optogenetic, and immunoelectron microscopic experiments suggest that the $\mathrm{Ca}_{\mathrm{v}} 3.2$ channelmediated regulation of glutamatergic transmission is a general phenomenon at central synapses.

\section{$C a_{V} 3.2$ channel-mediated local $\mathrm{Ca}^{2+}$ influx regulates NMDA transmission at synapses}

To determine how $\mathrm{Ca}_{\mathrm{V}} 3.2$ channels regulate both AMPA and NMDA responses, we performed additional experiments in CA1 neurons in cultured hippocampal slices. We included in culture medium NMDA-R antagonist APV or 5,7-dichlorokynurenic acid (DCKA) to block NMDA-R-dependent modification of AMPA transmission during the expression of $\mathrm{hCa}_{\mathrm{v}} 3.2$ (C456S)-GFP and $\mathrm{Ca}_{\mathrm{V}} 3.2 \mathrm{ct}-\mathrm{GFP}$ in CA1 neurons. We then examined the evoked EPSCs in these neurons in the normal bath solution. In the presence of APV or DCKA in culture medium, CA1 neurons expressing hCav3.2(C456S)-GFP had enhanced NMDA responses but the same AMPA responses compared with nearby nonexpressing neurons (Fig. 4A,B). Moreover, in the presence of the NMDA antagonists in culture medium, CA1 neurons expressing $\mathrm{Ca}_{\mathrm{v}} 3.2 \mathrm{ct}-\mathrm{GFP}$ had reduced NMDA responses but the same AMPA 


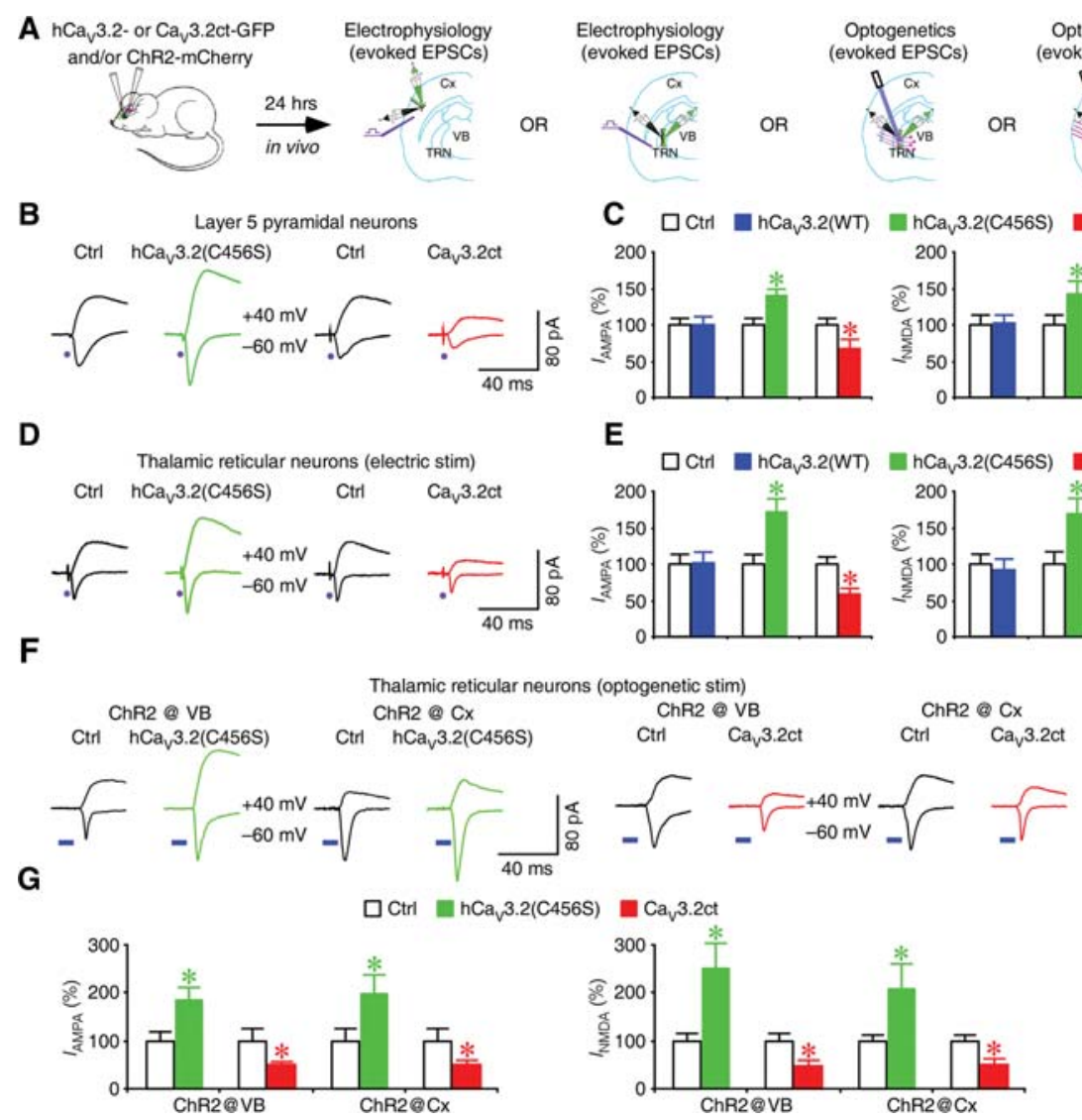

Figure 2. $\mathrm{Ca}_{\mathrm{V}} 3.2$ channels control glutamatergic transmission at various central synapses. $(A)$ Schematic drawing of in vivo experimental design with viral expression of hCa $3.2-\mathrm{GFP}$ or $\mathrm{Ca}_{\mathrm{V}} 3$.2ct-GFP in the barrel cortex or TRN and/or ChR2-mCherry in the ventrobasal thalamus or barrel cortex. $(B)$ Evoked AMPA-R-mediated $(-60 \mathrm{mV})$ and NMDA-R-mediated $(+40 \mathrm{mV})$ responses recorded from neighboring control nonexpressing (Ctrl) and hCa 3 .2-GFP-expressing or $\mathrm{Ca}_{\mathrm{v}} 3.2 \mathrm{ct}$-GFP-expressing cortical L5 pyramidal neurons in responses to electrical stimuli applied in acute slices. $(C)$ Values for AMPA responses in L5 pyramidal neurons expressing hCa 3.2 (WT)-GFP (Ctrl: -37.9 pA \pm 3.6 pA; wild type: $-37.6 \mathrm{pA} \pm 4.4 \mathrm{pA} ; n=16$ from five animals, $Z=-0.052, P=0.96)$, hCa $3.2(\mathrm{C} 456 \mathrm{~S})-\mathrm{GFP}(\mathrm{Ctrl}:-30.3 \mathrm{pA} \pm 2.9 \mathrm{pA}$; C456S: $-42.1 \mathrm{pA} \pm 3.2 \mathrm{pA} n=16$ from four animals, $Z=2.844, P<0.005$ ), and Cav3.2ct-GFP (Ctrl: $-37.8 \mathrm{pA} \pm 6.0 \mathrm{pA}$; Cav3.2ct: -26.3 $\mathrm{pA} \pm 4.0 \mathrm{pA} ; n=18$ from four animals, $Z=-2.373, P<0.05)$ and for NMDA responses in L5 pyramidal neurons expressing hCa 3.2 (WT)-GFP (Ctrl: $60.3 \mathrm{pA} \pm 7.7 \mathrm{pA}$; wild type: $61.5 \mathrm{pA} \pm 6.5 \mathrm{pA} ; n=16$ from five animals, $Z=0.103, P=0.92)$, hCa $3.2(\mathrm{C} 456 \mathrm{~S})-\mathrm{GFP}$ (Ctrl: $40.3 \mathrm{pA} \pm 4.9 \mathrm{pA} ; \mathrm{C} 456 \mathrm{~S}: 57.5 \mathrm{pA} \pm 6.8 \mathrm{pA} ; n=16$ from four animals, $Z=2.482, P<0.05)$, and (Ctrl: $42.3 \mathrm{pA} \pm 5.2 \mathrm{pA} ; \mathrm{Cav} 3.2 \mathrm{ct}: 28.6 \mathrm{pA}$ $\pm 3.7 \mathrm{pA} ; n=18$ from four animals, $Z=-2.243, P<0.05)$. (D) Evoked AMPA-R-mediated $(-60 \mathrm{mV})$ and NMDA-R-mediated $(+40 \mathrm{mV})$ responses recorded from neighboring control nonexpressing (Ctrl) and hCa 3 3.2-GFP-expressing or Ca 3 .2ct-GFP-expressing TRN neurons in response to electrical stimuli applied in acute slices. (E) Values for electrical stimulation-evoked AMPA responses in TRN neurons expressing hCav3.2(WT)-GFP (Ctrl: $-28.1 \mathrm{pA} \pm 3.1 \mathrm{pA}$ wild type: $-28.8 \mathrm{pA} \pm 3.4 \mathrm{pA} ; n=19$ from five animals, $Z=0.241, P=0.81$ ), hCa 3.2 (C456S)-GFP (Ctrl: $-19.4 \mathrm{pA} \pm 2.1 \mathrm{pA} ; \mathrm{C} 456 \mathrm{~S}:-33.4 \mathrm{pA} \pm 2.9 \mathrm{pA} ; n=18$ from eight animals, $Z=3.375, P<0.005)$, and Ca $3.2 \mathrm{ct}-\mathrm{GFP}(\mathrm{Ctrl}$ : $-48.3 \mathrm{pA} \pm 3.5 \mathrm{pA} ; \mathrm{Ca}_{\mathrm{V}} 3.2 \mathrm{ct}$ : $-28.3 \pm 3.6 \mathrm{pA} ; n=17$ from eight animals, $\left.Z=-3.101, P<0.005\right)$ and NMDA responses in TRN neurons expressing hCa $3.2(\mathrm{WT})$-GFP (Ctrl: $43.5 \mathrm{pA} \pm 5.6 \mathrm{pA}$; wild type: $39.8 \mathrm{pA} \pm 6.3 \mathrm{pA} ; n=19$ from five animals, $Z=-1.288, P=0.20$ ), hCav3.2 (C456S)-GFP (Ctrl: $29.7 \mathrm{pA} \pm 5.0$ pA; C456S: $50.3 \mathrm{pA} \pm 5.4 \mathrm{pA} ; n=18$ from eight animals, $Z=2.635, P<0.01$ ), and Ca $3.2 \mathrm{ct}-\mathrm{GFP}(\mathrm{Ctrl}$ : $52.1 \mathrm{pA} \pm 5.3 \mathrm{pA} ; \mathrm{Ca}_{\mathrm{V}} 3.2 \mathrm{ct}: 30.1 \mathrm{pA} \pm 3.8 \mathrm{pA} ; n=17$ from eight animals, $\left.Z=-2.769, P<0.01\right)$. (F) Evoked AMPA-R-mediated $(-60 \mathrm{mV})$ and NMDA-R-mediated $(+40 \mathrm{mV})$ responses recorded from neighboring control nonexpressing (Ctrl) and hCa $3.2-\mathrm{GFP}$-expressing or $\mathrm{Ca}_{\mathrm{v}} 3.2 \mathrm{ct}$-GFP-expressing TRN neurons in response to optogenetic stimuli applied in acute slices. (G) Values for AMPA responses in TRN neurons expressing hCa $3.2(\mathrm{C} 456 \mathrm{~S})$-GFP evoked by optogenetic stimulation of axons originated from the ventrobasal nucleus (VB) (Ctrl: $-41.1 \mathrm{pA} \pm 7.2 \mathrm{pA}$; $456 \mathrm{~S}:-75.5 \mathrm{pA} \pm 11.1 \mathrm{pA} ; n=16$ from nine animals, $Z=2.896, P<0.005)$ or the cortex (Ctrl: $-23.0 \mathrm{pA} \pm$ $5.4 \mathrm{pA}$; C456S: $-45.1 \mathrm{pA} \pm 9.4 \mathrm{pA} n=12$ from seven animals, $Z=2.589, P<0.05$ ) and TRN neurons expressing Cav3.2ct-GFP evoked by optogenetic stimulation of axons originated from the VB (Ctrl: $-75.4 \mathrm{pA} \pm 14.3 \mathrm{pA}$; Cav3.2ct: $-39.7 \mathrm{pA} \pm 3.7 \mathrm{pA} ; n=14$ from nine animals, $Z=-2.542, P<0.05)$ or the cortex $\left(\right.$ Ctrl: $-60.7 \mathrm{pA} \pm 7.1 \mathrm{pA} ; \mathrm{Ca}_{\mathrm{v}} 3.2 \mathrm{ct}:-32.8 \mathrm{pA} \pm 3.9 \mathrm{pA} ; n=12$ from seven animals, $Z=-2.824, P<$ 0.01 ) and for NMDA responses in TRN neurons expressing hCa 3.2 (C456S)-GFP evoked by optogenetic stimulation of axons originated from the VB (Ctrl: $30.3 \mathrm{pA} \pm 5.0 \mathrm{pA}$; C456S: $76.4 \mathrm{pA} \pm 15.4 \mathrm{pA} ; n=16$ from nine animals, $Z=2.792, P<0.01)$ or the cortex (Ctrl: $12.6 \mathrm{pA} \pm$ 1.6 pA; C456S: $26.1 \mathrm{pA} \pm 6.7 \mathrm{pA} ; n=12$ from seven animals, $Z=2.589, P<0.05$ ) and TRN neurons expressing Cav3.2ct-GFP evoked by optogenetic stimulation of axons originated from the $\mathrm{VB}\left(\mathrm{Ctrl}: 58.6 \mathrm{pA} \pm 9.2 \mathrm{pA} \mathrm{Ca}_{\mathrm{V}} 3.2 \mathrm{ct}: 28.9 \mathrm{pA} \pm 5.3 \mathrm{pA} ; n=14\right.$ from nine animals, $Z=-3.233, P<0.005$ ) or the cortex (Ctrl: $47.2 \mathrm{pA} \pm 6.7 \mathrm{pA} ; \mathrm{Ca}_{\mathrm{V}} 3.2 \mathrm{ct}: 24.7 \mathrm{pA} \pm 4.2 \mathrm{pA} ; n=12$ from seven animals, $Z=-2.981, P<0.01$ ). AMPA-R-mediated and NMDA-R-mediated current amplitudes and standard errors were normalized to average values from control cells. Asterisks indicate $P<0.05$ (Wilcoxon tests). 
A
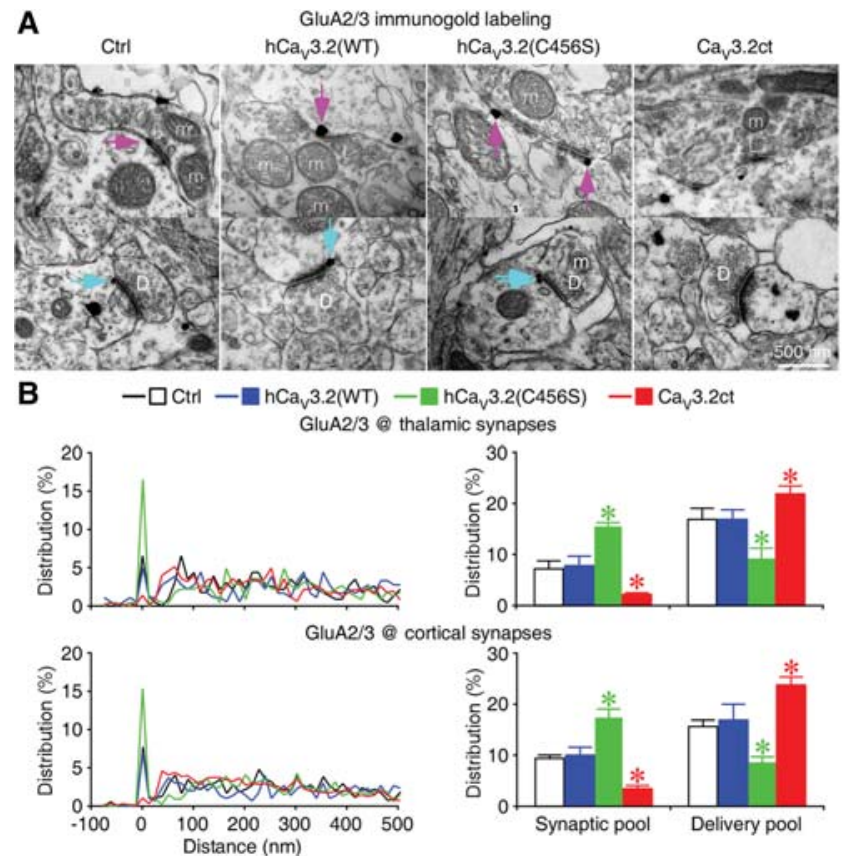
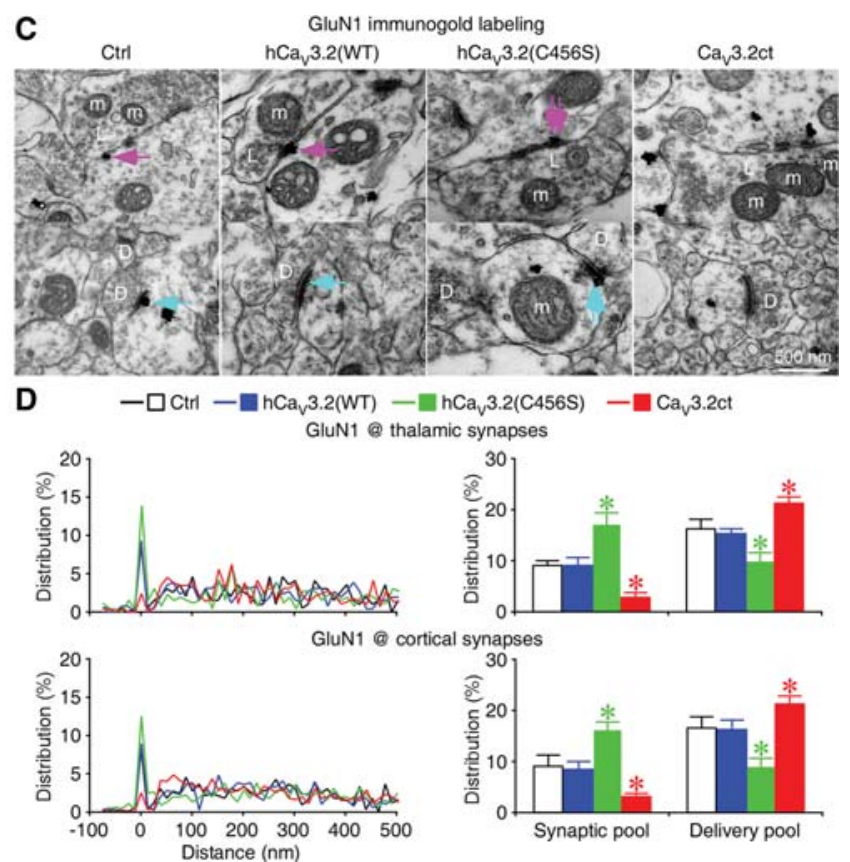

Figure 3. $\mathrm{Ca}_{\mathrm{V}} 3.2$ channels regulate synaptic expression of glutamatergic receptors. $(A) \mathrm{GluA} 2 / 3$ immunogold labeling at synapses in the control nonexpressing TRN and the TRN expressing hCav3.2(WT)-GFP, hCav3.2(C456S)-GFP, and Cav3.2ct-GFP. Arrows point to silverenhanced gold particles associated with PSDs postsynaptic to L (pink arrows) or D (cyan arrows) terminals. (B, left) Relative distributions of GluA2/3 silver-gold particles at thalamic synapses contacted by $\mathrm{L}$ terminals in the TRN expressing hCav $3.2(\mathrm{WT})-\mathrm{GFP}, \mathrm{hCa} 3.2$ (C456S)-GFP, or Ca 3 3.2ct-GFP (wild type: $n=178$ particles from 147 synapses; C456S: $n=227$ particles from 207 synapses; Ca $3.2 \mathrm{ct}: n$ $=523$ particles from 443 synapses) compared with that in the control nonexpressing TRN (Ctrl: $n=232$ particles from 202 synapses) as well as cortical synapses contacted by D terminals in the TRN expressing hCa $3.2(\mathrm{WT})$-GFP, hCa $3.2(\mathrm{C} 456 \mathrm{~S})-\mathrm{GFP}$, and Ca $3.2 \mathrm{ct}-\mathrm{GFP}$ (wild type: $n=298$ particles from 232 synapses; C456S: $n=545$ particles from 502 synapses; Ca $3.2 c t: n=993$ particles from 851 synapses) terminals compared with that in the control nonexpressing TRN (Ctrl: $n=563$ from 469 synapses). (Right) Average percentages of GluA2/3 silver-gold particles in synaptic pools of thalamic synapses in the TRN expressing hCav3.2(WT)-GFP, hCav3.2(C456S)-GFP, and $\mathrm{Ca}_{\mathrm{V}} 3.2$ ct-GFP (wild type: $8.5 \% \pm 2.1 \%, n=12$ animals, $U=75.0, P=0.89$; C456S: $16.6 \% \pm 1.2 \%, n=12$ animals, $U=126.5, P<0.001$; $\mathrm{Ca}_{\mathrm{V}} 3.2 \mathrm{ct}: 2.2 \% \pm 0.7 \%, n=12$ animals, $\left.U=34.0, P<0.05\right)$ compared with that in the control nonexpressing TRN (Ctrl: $7.7 \% \pm 1.7 \%, n$ $=12$ animals); in deliverable pools of thalamic synapses in the TRN expressing hCav3.2(WT)-GFP, hCav3.2(C456S)-GFP, and Ca $3.2 \mathrm{ct}-$ GFP (wild type: $18.4 \% \pm 1.9 \%, n=12$ animals, $U=81.0, P=0.63$; C456S: $10.0 \% \pm 2.2 \%, n=12$ animals, $U=118.0, P<0.01 ; C a$ V 3.2 ct: $24.0 \% \pm 1.7 \%, n=12$ animals, $U=117.0, P<0.05)$ compared with that in the control nonexpressing TRN $(\mathrm{Ctrl}: 18.3 \% \pm 2.5 \%, n=12$ animals); in synaptic pools of cortical synapses in the TRN expressing hCav3.2(WT)-GFP, hCav3.2(C456S)-GFP, and Cav3.2ct-GFP (wild type: $10.1 \% \pm 1.5 \%, n=12$ animals, $U=78.5, P=0.71$; C456S: $17.3 \% \pm 1.7 \%, n=12$ animals, $U=130.0, P<0.0005 ; \mathrm{Ca} 3.2 \mathrm{ct}: 3.3 \% \pm$ $0.8 \%, n=12$ animals, $U=10.0, P<0.005$ ) compared with that in control nonexpressing TRN (Ctrl: $9.4 \% \pm 0.7 \%, n=12$ animals); and in deliverable pools of cortical synapses in the TRN expressing hCa 3.2 (WT)-GFP, hCa 3.2 (C456S)-GFP, and Cav $3.2 \mathrm{ct}-\mathrm{GFP}$ (wild type: $16.8 \% \pm 3.1 \%, n=12$ animals, $U=71.0, P=0.98$; C456S: $8.4 \% \pm 1.2 \%, n=12$ animals, $U=16.0, P<0.001 ;$ Cav $3.2 \mathrm{ct}: 23.7 \% \pm 1.7 \%, n=$ 12 animals, $U=122.0, P<0.005)$ compared with that in the control nonexpressing TRN (Ctrl: $15.6 \% \pm 1.3 \%, n=12$ animals). (C) GluN1 immunogold labeling at synapses in the control nonexpressing TRN and the TRN expressing hCav $3.2(\mathrm{WT})$-GFP, hCa 3.2 (C456S)-GFP, and Ca 3 3.2ct-GFP. Arrows point to silver-enhanced gold particles associated with the PSDs postsynaptic to L (pink arrows) or $\mathrm{D}$ (cyan arrows) terminals. ( $D$, left) Relative distributions of GluN1 silver-gold particles at thalamic synapses contacted by $\mathrm{L}$ terminals in the TRN expressing $\mathrm{hCa}_{\mathrm{V}} 3.2(\mathrm{WT})$-GFP, hCa 3.2 (C456S)-GFP, and $\mathrm{Ca}_{\mathrm{V}} 3.2 \mathrm{ct}-\mathrm{GFP}$ (wild type: $n=262$ particles from 230 synapses; C456S: $n=257$ particles from 196 synapses; Ca 3.2 ct: $n=301$ particles from 238 synapses) compared with that in the control nonexpressing TRN (Ctrl: $n=197$ particles from 175 synapses) as well as cortical synapses contacted by D terminals in the TRN expressing hCa 3.2 (WT)GFP, hCa 3.2 (C456S)-GFP, and Cav3.2ct-GFP (wild type: $n=399$ particles from 343 synapses; C456S: $n=444$ particles from 339 synapses; $\mathrm{Ca}_{\mathrm{V}} 3.2 \mathrm{ct}: n=576$ particles from 456 synapses) compared with that in the control nonexpressing TRN (Ctrl: $n=334$ particles from 300 synapses). (Right) Average percentages of GluN1 silver-gold particles in synaptic pools of thalamic synapses in the TRN expressing hCa 3.2 (WT)-GFP, hCa 3.2 (C456S)-GFP, and Cav3.2ct-GFP (wild type: $9.3 \% \pm 1.5 \%, n=12$ animals, $U=70.5, P=0.95 ;$ C456S: $17.4 \% \pm 1.8 \%, n=$ 14 animals, $U=127.5, P<0.05 ; \mathrm{Ca}_{\mathrm{v}} 3.2 \mathrm{ct}: 3.4 \% \pm 0.8 \%, n=12$ animals, $\left.U=32.5, P<0.05\right)$ compared with that in the control nonexpressing TRN (Ctrl: $10.0 \% \pm 2.3 \%, n=12$ animals); in deliverable pools of thalamic synapses in the TRN expressing hCa 3.2 (WT)-GFP, hCa 3.2 (C456S)-GFP, and Cav3.2ct-GFP (wild type: $17.7 \% \pm 2.1 \%, n=12$ animals, $U=77.0, P=0.80$; C456S: $10.0 \% \pm 1.9 \%, n=14$ animals, $U=$ 36.0, $P<0.05$; Cav3.2ct: $23.2 \% \pm 1.7 \%, n=12$ animals, $U=106.5, P<0.005$ ) compared with that in control nonexpressing TRN (Ctrl: $18.1 \% \pm 2.5 \%, n=12$ animals); in synaptic pools of cortical synapses in the TRN expressing $\mathrm{hCa}_{\mathrm{V}} 3.2(\mathrm{WT})$-GFP, hCa $3.2(\mathrm{C} 456 \mathrm{~S})-\mathrm{GFP}$, and $\mathrm{Ca}_{\mathrm{V}} 3.2 \mathrm{ct}-\mathrm{GFP}$ (wild type: $9.8 \% \pm 1.7 \%, n=12$ animals, $U=59.0, P=0.47$; C456S: $17.6 \% \pm 2.4 \%, n=14$ animals, $U=129.0, P<0.05$; Cav3.2ct: $3.2 \% \pm 0.8 \%, n=12, U=7.5, P<0.005)$ compared with that in the control nonexpressing TRN $(\mathrm{Ctrl}: 10.0 \% \pm 0.9 \%, n=12$ animals); and in deliverable pools of cortical synapses in the TRN expressing hCav3.2(WT)-GFP, hCav3.2(C456S)-GFP, and Cav3.2ct-GFP (wild type: $16.8 \% \pm 0.7 \%, n=12$ animals, $U=67.0, P=0.80$; C456S: $10.4 \% \pm 1.7 \%, n=14$ animals, $U=29.0, P<0.01 ; C a_{\mathrm{V}} 3.2 \mathrm{ct}: 23.1 \% \pm$ $1.4 \%, n=12$ animals, $U=109.0, P<0.05$ ) compared with that in the control nonexpressing TRN (Ctrl: $17.8 \% \pm 2.0 \%, n=12$ animals). Note the complementary changes in the amounts of GluA2/3 and GluN1 silver-gold particles in the PSD and the nearby deliverable pool of both thalamic and cortical synapses in the TRN in all experiments. Asterisks indicate $P<0.05$ (Mann-Whitney test). 


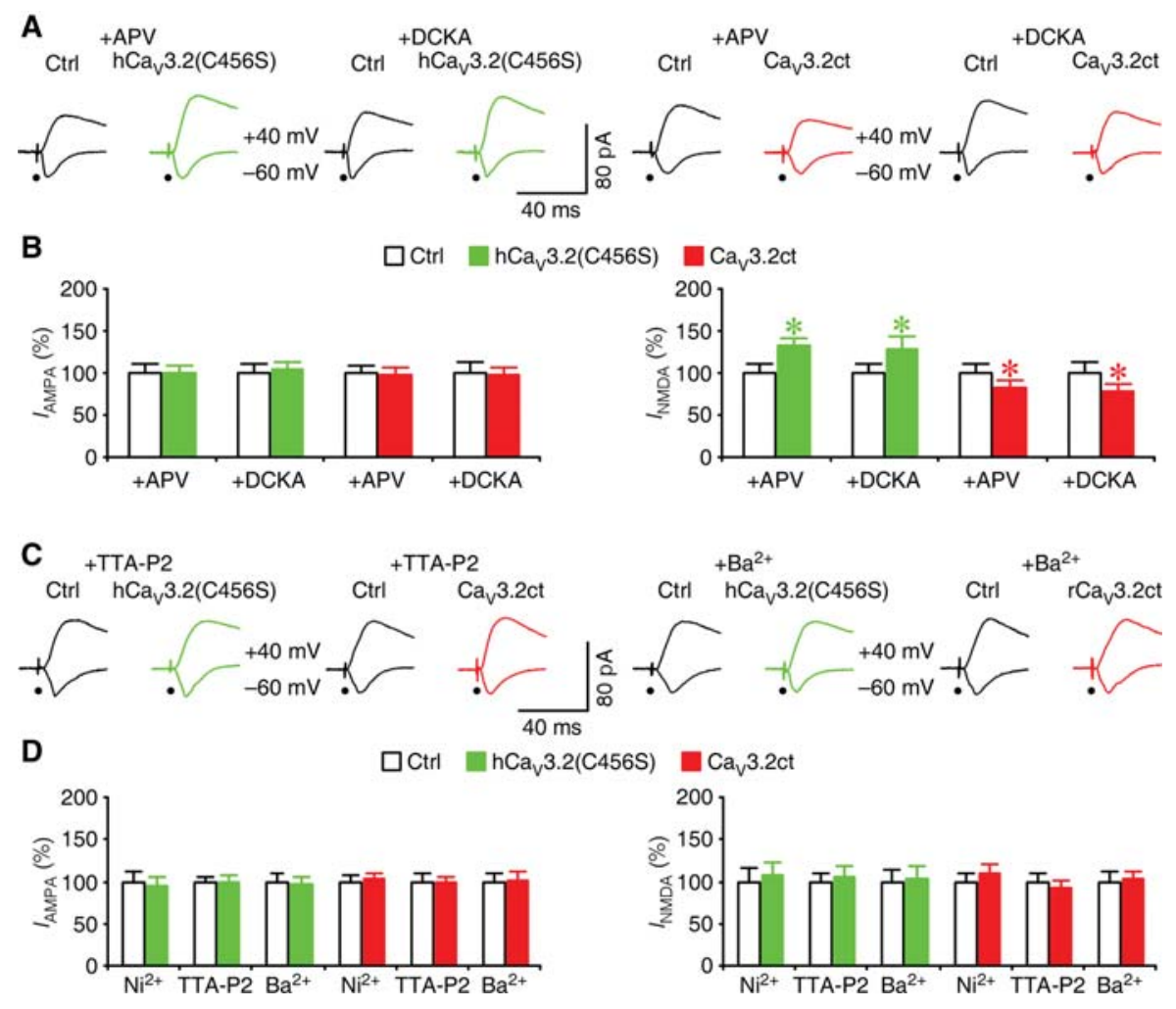

Figure 4. $\mathrm{Ca}_{\mathrm{v}} 3.2$ channels control NMDA transmission via regulating local $\mathrm{Ca}^{2+}$ influx at synapses. $(A)$ Evoked AMPA-R-mediated $(-60 \mathrm{mV})$ and NMDA-R-mediated $(+40 \mathrm{mV})$ responses recorded from neighboring control nonexpressing $(\mathrm{Ctrl})$ and hCa 3.2 -GFP-expressing or $\mathrm{Ca}_{\mathrm{V}} 3.2 \mathrm{ct}$-GFP-expressing CA1 neurons cultured in medium containing $100 \mu \mathrm{M}$ DL-APV or $5 \mu \mathrm{M}$ DCKA. $(B)$ Values for AMPA responses in CA1 neurons expressing hCa 3.2 (C456S)-GFP and $\mathrm{Ca}_{\mathrm{V}} 3.2$ ct-GFP cultured in medium containing $100 \mu \mathrm{M}$ DL-APV (Ctrl: -18.1 $\mathrm{pA} \pm 1.8 \mathrm{pA} ; \mathrm{C} 456 \mathrm{~S}:-18.0 \mathrm{pA} \pm 1.6 \mathrm{pA} ; n=22$ from 12 animals, $Z=-0.114, P=0.91 ; \mathrm{Ctrl}:-30.4 \mathrm{pA} \pm 2.4 \mathrm{pA} ; \mathrm{Cav} 3.2 \mathrm{ct}:-30.0 \mathrm{pA} \pm 2.6 \mathrm{pA} ; n$ $=20$ from eight animals, $Z=-0.075, P=0.94$ ) or $5 \mu \mathrm{M} \mathrm{DCKA}$ (Ctrl: $-31.1 \mathrm{pA} \pm 3.2 \mathrm{pA}$; C456S: $-32.4 \mathrm{pA} \pm 2.6 \mathrm{pA} ; n=20$ from eight animals, $Z=0.635, P=0.53$; Ctrl: $-32.8 \mathrm{pA} \pm 4.0 \mathrm{pA} ; \mathrm{Ca}_{\mathrm{v}} 3.2 \mathrm{ct}:-31.8 \mathrm{pA} \pm 2.9 \mathrm{pA}, n=22$ from eight animals, $\left.Z=-0.146, P=0.88\right)$ and for NMDA responses in CA1 neurons expressing hCav3.2(C456S)-GFP and Cav3.2ct-GFP cultured in medium containing $100 \mu M$ DL-APV (Ctrl: $41.2 \mathrm{pA} \pm 4.2 \mathrm{pA}$; $456 \mathrm{~S}: 54.3 \mathrm{pA} \pm 4.0 \mathrm{pA} ; n=22$ from 12 animals, $Z=2.776, P<0.01$; Ctrl: $-109.6 \mathrm{pA} \pm 11.1 \mathrm{pA} ; \mathrm{Ca} 3.2 \mathrm{ct}:-91.0 \mathrm{pA} \pm$ $9.5 \mathrm{pA} ; n=20$ from eight animals, $Z=-2.128, P<0.05$ ) or $5 \mu \mathrm{M}$ DCKA (Ctrl: $60.2 \mathrm{pA} \pm 8.0 \mathrm{pA} ; \mathrm{C} 456 \mathrm{~S}: 87.2 \mathrm{pA} \pm 10.9 \mathrm{pA} ; n=20$ from eight animals, $Z=2.016, P<0.05$; Ctrl: $86.7 \mathrm{pA} \pm 11.9 \mathrm{pA}$; Cav3.2ct: $68.7 \mathrm{pA} \pm 7.5 \mathrm{pA} ; n=22$ from eight animals, $Z=-2.386, P<$ 0.05). (C) Evoked AMPA-R-mediated $(-60 \mathrm{mV})$ and NMDA-R-mediated $(+40 \mathrm{mV})$ responses recorded from neighboring control nonexpressing (Ctrl) and $\mathrm{hCa}_{\mathrm{V}} 3$.2-GFP-expressing or $\mathrm{Ca}_{\mathrm{V}} 3.2 \mathrm{ct}$-GFP-expressing rat CAl neurons cultured in medium containing $1 \mu \mathrm{M}$ TTA$\mathrm{P} 2$ or medium with $\mathrm{Ca}^{2+}$ replaced with $\mathrm{Ba}^{2+}$. (D) Values for AMPA responses in rat CA1 neurons expressing hCa $3.2(\mathrm{C} 456 \mathrm{~S})-\mathrm{GFP}$ and $\mathrm{Ca}_{\mathrm{V}} 3.2 \mathrm{ct}-\mathrm{GFP}$ cultured in medium containing $50 \mu \mathrm{M} \mathrm{Ni}^{2+}$ (Ctrl: $-19.6 \mathrm{pA} \pm 2.3 \mathrm{pA} ; \mathrm{C} 456 \mathrm{~S}:-18.4 \mathrm{pA} \pm 2.2 \mathrm{pA} ; n=18$ from 12 animals, $Z=-1.067, P=0.29$; Ctrl: $-23.9 \mathrm{pA} \pm 1.8 \mathrm{pA}$; Cav3.2ct: $-24.5 \mathrm{pA} \pm 1.6 \mathrm{pA} ; n=22$ from eight animals, $Z=0.568, P=0.57)$ or $1 \mu \mathrm{M}$ TTAP2 (Ctrl: $-24.8 \mathrm{pA} \pm 1.4 \mathrm{pA}$; $456 \mathrm{~S}:-24.3 \mathrm{pA} \pm 2.4 \mathrm{pA} ; n=24$ from eight animals, $Z=-0.257, P=0.80 ; \mathrm{Ctrl}:-29.2 \mathrm{pA} \pm 2.6 \mathrm{pA} ; \mathrm{Ca}_{\mathrm{v}} 3.2 \mathrm{ct}:$ $-28.7 \mathrm{pA} \pm 1.9 \mathrm{pA} ; n=20$ from eight animals, $Z=-0.261, P=0.79)$ or medium with $\mathrm{Ca}^{2+}$ replaced with $\mathrm{Ba}^{2+}\left(\mathrm{Ctrl}^{2}:-29.5 \mathrm{pA} \pm 2.8 \mathrm{pA}\right.$; C456S: $-28.3 \mathrm{pA} \pm 2.7 \mathrm{pA} ; n=20$ from eight animals, $Z=-0.784, P=0.43$; Ctrl: $-34.2 \mathrm{pA} \pm 3.0 \mathrm{pA} ; \mathrm{Ca}_{\mathrm{v}} 3.2 \mathrm{ct}:-34.3 \mathrm{pA} \pm 3.8 \mathrm{pA} ; n=22$ from eight animals, $Z=-0.308, P=0.76)$ and for NMDA responses in rat CAl neurons expressing hCa $3.2(\mathrm{C} 456 \mathrm{~S})-\mathrm{GFP}$ and $\mathrm{Ca}$ 的3.2ctGFP cultured in medium containing $50 \mu \mathrm{M} \mathrm{Ni}^{2+}(\mathrm{Ctrl}: 40.4 \mathrm{pA} \pm 6.3 \mathrm{pA} ; \mathrm{C} 456 \mathrm{~S}: 43.2 \mathrm{pA} \pm 6.1 \mathrm{pA} ; n=18$ from 12 animals, $Z=0.980$, $P=0.33$; Ctrl: $65.2 \mathrm{pA} \pm 5.9 \mathrm{pA} ; \mathrm{Ca}_{\mathrm{V}} 3.2 \mathrm{ct}: 71.1 \mathrm{pA} \pm 7.2 \mathrm{pA} ; n=22$ from eight animals, $Z=0.341, P=0.73$ ) or $1 \mu \mathrm{M}$ TTA-P2 (Ctrl: 65.7 $\mathrm{pA} \pm 6.1 \mathrm{pA} ; \mathrm{C} 456 \mathrm{~S}: 68.9 \mathrm{pA} \pm 8.0 \mathrm{pA} ; n=24$ from eight animals, $Z=0.086, P=0.93$; Ctrl: $60.7 \mathrm{pA} \pm 6.1 \mathrm{pA} ; \mathrm{Cav}_{3} .2 \mathrm{ct}: 56.4 \mathrm{pA} \pm 5.1 \mathrm{pA} ;$ $n=20$ from eight animals, $Z=-0.747, P=0.46)$ or medium with $\mathrm{Ca}^{2+}$ replaced with $\mathrm{Ba}^{2+}(\mathrm{Ctrl}: 78.0 \mathrm{pA} \pm 10.1 \mathrm{pA} ; \mathrm{C} 456 \mathrm{~S}: 81.0 \mathrm{pA} \pm 11.3$ pA; $n=20$ from eight animals, $Z=-0.112, P=0.91$; Ctrl: $101.9 \mathrm{pA} \pm 11.5 \mathrm{pA}$; Ca $3.2 \mathrm{ct}: 104.2 \mathrm{pA} \pm 9.5 \mathrm{pA} ; n=22$ from eight animals, $Z=0.243, P=0.81$. AMPA-R-mediated and NMDA-R-mediated current amplitudes and standard errors were normalized to average values from control cells. Asterisks indicate $P<0.05$ (Wilcoxon tests).

responses compared with nearby nonexpressing neurons (Fig. 4A,B). These results indicate that NMDA antagonists selectively block the $\mathrm{Ca}_{\mathrm{V}} 3.2$ channel-mediated effects on AMPA transmission but not NMDA transmission, suggesting that the effects on AMPA responses are secondary to the changes in NMDA responses.
To determine whether activation of $\mathrm{Ca}_{\mathrm{V}} 3.2$ channels is required for the regulation of AMPA and NMDA responses, we included $50 \mu \mathrm{M} \mathrm{Ni}^{2+}$, a T- and R-type $\mathrm{Ca}^{2+}$ channel antagonist, or $1 \mu \mathrm{M}$ TTA-P2, a selective T-type $\mathrm{Ca}^{2+}$ channel antagonist, in culture medium during the expression of hCa $3.2(\mathrm{C} 456 \mathrm{~S})-\mathrm{GFP}$ or $\mathrm{Ca}_{\mathrm{V}} 3.2 \mathrm{ct}-\mathrm{GFP}$ in CA1 neurons. 
We then examined evoked EPSCs in CA1 neurons in the normal bath solution. In the presence of $50 \mu \mathrm{M} \mathrm{Ni}{ }^{2+}$ or $1 \mu \mathrm{M}$ TTA-P2 in culture medium, CA1 neurons expressing hCa $3.2(\mathrm{C} 456 \mathrm{~S})-\mathrm{GFP}$ or $\mathrm{Ca}_{\mathrm{v}} 3.2 \mathrm{ct}-\mathrm{GFP}$ had the same AMPA and NMDA responses compared with nearby control nonexpressing neurons (Fig. 4C,D). These results suggest that pharmacological blockade of $\mathrm{Ca}_{\mathrm{V}} 3.2$ channel activity blocks the potentiation of AMPA and NMDA responses in $\mathrm{hCa}_{\mathrm{v}} 3.2$ (C456S)-GFP-expressing neurons and occludes the depression of AMPA and NMDA responses in $\mathrm{Ca}_{\mathrm{v}} 3.2 \mathrm{ct}-\mathrm{GFP}$-expressing neurons. These results suggest that activation of $\mathrm{Ca}_{\mathrm{v}} 3.2$ channels is required for the $\mathrm{Ca}_{\mathrm{v}} 3.2$ channel-dependent regulation of glutamatergic transmission.

We wished to know whether synaptic activity drives the activation of $\mathrm{Ca}_{\mathrm{v}} 3.2$ channels to regulate glutamatergic transmission, since low-threshold calcium channels, including $\mathrm{Ca}_{\mathrm{V}} 3.2$ channels, can be activated by synaptic input at the RMP. To test this idea, we included 12 $\mathrm{mM} \mathrm{MgCl} 2$ or $4 \mu \mathrm{MTTX}$, which depresses or blocks synaptic transmission (Zhu et al. 2000; McCormack et al. 2006), in culture medium during expression of $\mathrm{hCa}_{\mathrm{V}} 3.2$ (C456S)-GFP and Cav3.2ct-GFP in CA1 neurons. We then examined the evoked EPSCs in these neurons in the normal bath solution. In the presence of high $\mathrm{Mg}^{2+}$ or TTX in culture medium, CA1 neurons expressing hCa $3.2(\mathrm{C} 456 \mathrm{~S})$-GFP or $\mathrm{Ca}_{\mathrm{V}} 3.2 \mathrm{ct}-\mathrm{GFP}$ had the same AMPA and NMDA responses compared with nearby nonexpressing neurons (Supplemental Fig. S7). These results suggest that synaptic activity activates $\mathrm{Ca}_{\mathrm{v}} 3.2$ channels to regulate glutamatergic transmission.

Because the above-reported data showed that activation of $\mathrm{Ca}_{\mathrm{v}} 3.2$ channels did not significantly alter the basic membrane properties, we speculated that the $\mathrm{Ca}_{\mathrm{v}} 3.2$ channel-dependent regulation of glutamatergic transmission might be mediated by calcium influx via the channels. To test this possibility, we cultured CA1 neurons in medium in which calcium ions were replaced with barium ions, which are equally or more efficient charge carriers for $\mathrm{Ca}_{\mathrm{v}} 3.2$ channels (McRory et al. 2001). Substitution of calcium ions with barium ions prevented the $\mathrm{hCa}_{\mathrm{v}} 3.2(\mathrm{C} 456 \mathrm{~S})$-induced potentiation and the $\mathrm{Ca}_{\mathrm{V}} 3.2 \mathrm{ct}$-induced depression in CA1 neurons (Fig. $4 C, D)$. Collectively, these results suggest that synaptic activity activates $\mathrm{Ca}_{\mathrm{v}} 3.2$ channels and induces calcium influx that potentiates NMDA responses prior to AMPA responses.

To directly verify that activation of $\mathrm{Ca}_{\mathrm{V}} 3.2$ channels induces calcium influx, we imaged $\mathrm{Ca}^{2+}$ transients in CA1 neurons expressing hCav3.2-GFP and $\mathrm{Ca}_{\mathrm{V}} 3.2 \mathrm{ct}-\mathrm{GFP}$ in cultured hippocampal slices. Simultaneously, we loaded the green $\mathrm{Ca}^{2+}$-sensitive indicator Fluo-5F and the red $\mathrm{Ca}^{2+}$-insensitive indicator Alexa 594 into expressing and neighboring nonexpressing CA1 neuron pairs and recorded the back-propagating action potential (bAP)-evoked fluorescence changes in nearby pairs of spines and their parent dendrites of these neurons (Fig. 5A,B). We found that the spines, but not the parent dendrites, of neurons expressing hCa 3.2 (C456S)-GFP had significantly increased bAP-evoked $\mathrm{Ca}^{2+}$ transients $\left(\Delta[\mathrm{Ca}]_{\mathrm{bAP}}\right)$ compared with those of nonexpressing neurons (Fig. 5C). In contrast, the spines, but not the parent dendrites, of neurons expressing $\mathrm{Ca}_{\mathrm{V}} 3.2 \mathrm{ct}-\mathrm{GFP}$ had significantly reduced $\Delta[\mathrm{Ca}]_{\mathrm{bAP}}$ (by $\sim 50 \%$ ) compared with those of nonexpressing neurons (Fig. 5C). As controls, the spines and parent dendrites of neurons expressing $\mathrm{hCa}_{\mathrm{V}} 3.2(\mathrm{WT})$-GFP had the same $\Delta[\mathrm{Ca}]_{\mathrm{bAP}}$ compared with those from nonexpressing neurons (Fig. $5 \mathrm{C}$ ). To confirm that synaptic $\Delta[\mathrm{Ca}]_{\mathrm{bAP}}$ is mediated by $\mathrm{T}$-type calcium channels, we carried out additional pharmacological experiments. Including $1 \mu \mathrm{M}$ TTA-P2 or $50 \mu \mathrm{M} \mathrm{Ni}^{2+}$ in the bath solution blocked the hCa $3.2(\mathrm{C} 456 \mathrm{~S})$-induced increase in $\Delta[\mathrm{Ca}]_{\mathrm{bAP}}$ and occluded the $\mathrm{Ca}_{\mathrm{V}} 3.2 \mathrm{ct}$-induced decrease in $\Delta[\mathrm{Ca}]_{\mathrm{bAP}}$ at the spines (Fig. 5C). These results confirm that activation of $\mathrm{Ca}_{\mathrm{v}} 3.2$ channels contributes to local calcium influx at the synapses.

To define the contribution of $\mathrm{Ca}_{\mathrm{V}} 3.2$ channels to the T-type calcium channel-mediated calcium influx at the synapses, we imaged $\mathrm{Ca}^{2+}$ transients in CA1 neurons in acutely prepared slices after $\sim 18 \mathrm{~h}$ of in vivo expression of $\mathrm{hCa}_{\mathrm{V}} 3$.2-GFP and $\mathrm{Ca}_{\mathrm{V}} 3.2 \mathrm{ct}-\mathrm{GFP}$. In these experiments, we included L-, N-, P/Q-, and R-type channel antagonists, $10 \mu \mathrm{M}$ nimodipine, $1 \mu \mathrm{M}$ CTX-MVIIC, and $0.3 \mu \mathrm{M}$ SNX482 in the bath solution to isolate T-type calcium currents. In the presence of nimodipine, CTX-MVIIC, and SNX-482, the spines, but not the parent dendrites, of neurons expressing hCa 3.2 (C456S)-GFP had significantly increased $\Delta[\mathrm{Ca}]_{\mathrm{bAP}}$. Moreover, after the isolation of T-type calcium currents, the spines, but not the parent dendrites, of neurons expressing $\mathrm{Ca}_{\mathrm{v}} 3.2 \mathrm{ct}-\mathrm{GFP}$ had substantially reduced $\Delta[\mathrm{Ca}]_{\mathrm{bAP}}($ by $\sim 75 \%$ ) (Fig. $5 \mathrm{C}$ ). Collectively, these results show that endogenous $\mathrm{Ca}_{\mathrm{V}} 3.2$ channels are the primary contributors to the T-type channel-mediated calcium influx at synapses.

We wanted to learn how the CAE-linked gain-of-function hCav3.2(C456S) mutant enhances calcium influx at the synapses. Hence, we analyzed $\mathrm{Ca}^{2+}$ transients in single spines in CA1 neurons of acutely prepared slices after in vivo expression of $\mathrm{hCa}_{\mathrm{V}} 3.2$ using optical fluctuation analysis (Sabatini and Svoboda 2000; Yasuda et al. 2003). Single spines contain a small number of calcium channels $(N)$ that open independently with a probability per action potential $(p)$. The actual number of calcium channels opened by an action potential is governed by the binomial distribution. It is thus possible to extract $N$ and $p$ of calcium channels in individual spines using optical fluctuation analyses. As with previous studies (Sabatini and Svoboda 2000; Yasuda et al. 2003), we found that the spines of both expressing and nonexpressing neurons had large trial-to-trial fluctuations in fluorescence, and, in some of these spines, bAPs occasionally failed to trigger a rapid rise in fluorescence (Fig. 5D). Because the coefficient of variation of the number of open channels is $C V_{\text {open }}=[(1-p) / \mathrm{N} p]^{1 / 2}$ and the probability of failure is $P(0)=(1-p)^{\mathrm{N}}$, we used these two equations to calculate $p$ and $N$ of $\mathrm{Ca}_{\mathrm{V}} 3.2$ channels in the spines of expressing and nonexpressing neurons (Fig. 5D,E). We found that $\mathrm{hCa}_{\mathrm{V}} 3.2$ (C456S)-GFP-expressing neurons had $\sim 35 \%$ increased $p$ but the same $N$ compared with neighboring control nonexpressing neurons $(n=7)$, whereas hCa $3.2(\mathrm{WT})$ - 

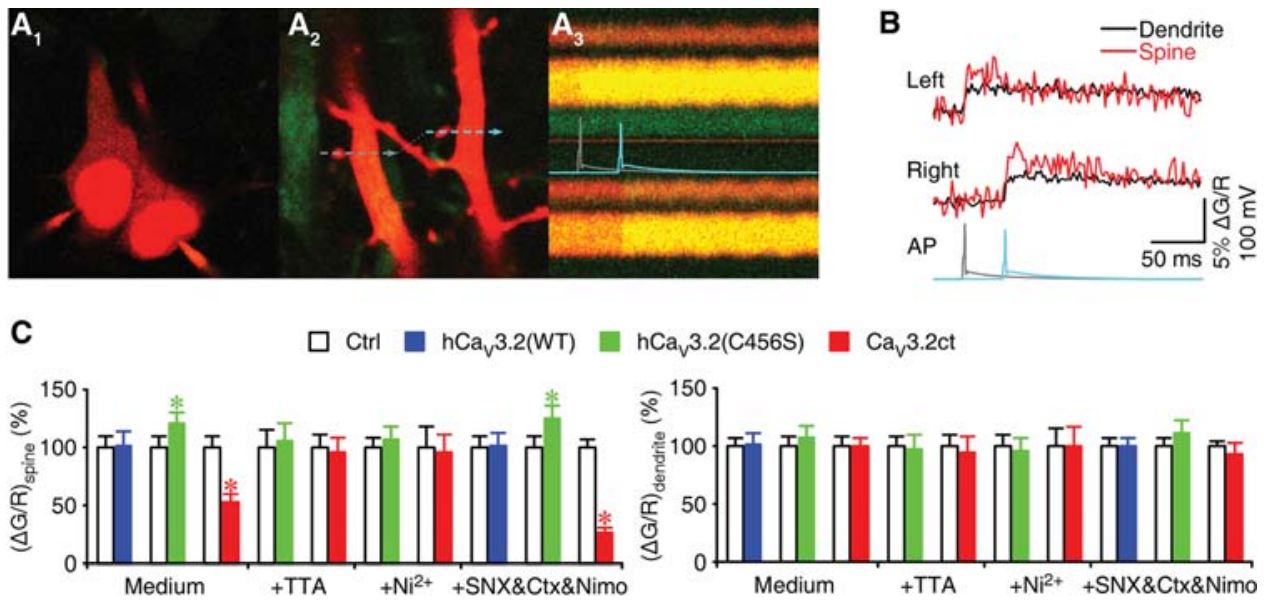

$\mathrm{hCa} 3.2(\mathrm{C} 456 \mathrm{~S})$

$\mathrm{Ca}_{\mathrm{v}} 3.2 \mathrm{ct}$
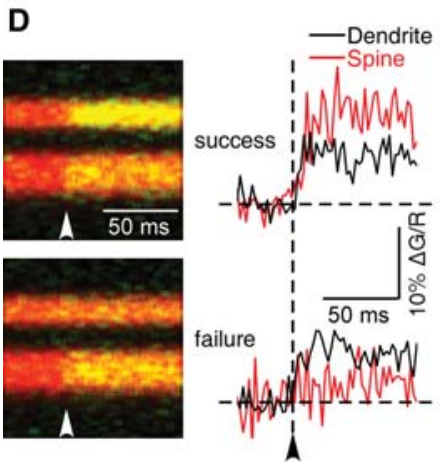

E

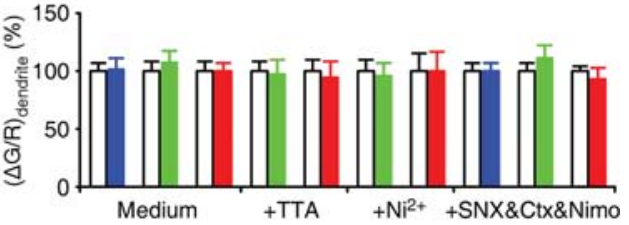

$\square \mathrm{Ctrl} \square \mathrm{nCaV}$ 3.2(WT)

$\mathbf{F}$ = $\mathrm{hCa}_{\mathrm{V}} 3.2(\mathrm{C} 456 \mathrm{~S})$
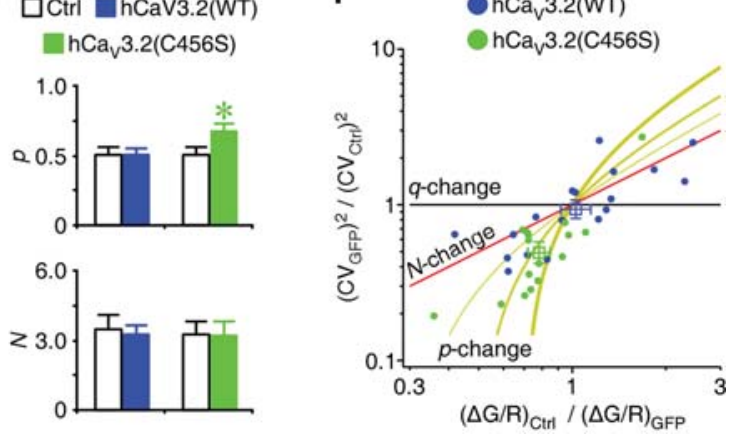

Figure 5. A small number of $\mathrm{Ca}$ 3.2 channels contribute to primary calcium influx at synapses. $\left(A_{1}-A_{3}\right.$, left $)$ Image of a pair of neighboring hCav3.2(WT)-GFP-expressing (left) and control nonexpressing (right) CA1 neurons loaded with $200 \mu \mathrm{M} \mathrm{Fluo-5F}$ (green) and $20 \mu \mathrm{M} \mathrm{Alexa} 594$ (red). The fluorescence of GFP was masked by the fluorescence of Alexa 594. (Middle) Image of a nearby pair of spines and their parent dendrites located $\sim 75 \mu \mathrm{m}$ from the soma of the CA1 neuron pairs illustrated in $A_{1}$. (Right) Line scan imaging of calcium fluorescence signals elicited by the bAPs evoked with somatic current injections in expressing (left neuron; gray trace) and nonexpressing (right neuron; cyan trace) neurons. $(B) \Delta[\mathrm{Ca}]_{\mathrm{bAP}}$ in spines and parent dendrites quantified from $A_{3}$. $(C)$ Values for $\Delta[\mathrm{Ca}]_{\mathrm{bAP}}$ in spines of CA1 neurons cultured in normal medium and bathed in normal solution (Ctrl: $2.29 \% \pm 0.22 \%$; wild type: $2.31 \% \pm 0.31 \% ; n=17$ from eight animals, $Z=-0.118, P=$ 0.91; Ctrl: $2.40 \% \pm 0.22 \%$; C456S: $2.90 \% \pm 0.24 \% ; n=20$ from 16 animals, $Z=2.072, P<0.05$; Ctrl: $3.63 \% \pm 0.38 \%$; Cav3.2ct: $1.91 \% \pm$ $0.24 \% ; n=18$ from 12 animals, $Z=-3.506, P<0.0005)$, cultured in normal medium and bathed in solution containing $1 \mu M$ TTA-P2 (Ctrl: $1.17 \% \pm 0.17 \%$; C456S: $1.23 \% \pm 0.19 \% ; n=15$ from nine animals, $Z=-0.220, P=0.83 ;$ Ctrl: $1.67 \% \pm 0.19 \% ; C a v 3.2 \mathrm{ct}: 1.60 \% \pm$ $0.21 \% ; n=14$ from eight animals, $Z=-0.157, P=0.88$ ), or cultured in normal medium and bathed in solution containing $50 \mu \mathrm{M} \mathrm{Ni}{ }^{2+}$ (Ctrl: $1.24 \% \pm 0.11 \%$; C456S: $1.32 \% \pm 0.13 \% ; n=17$ from seven animals, $Z=0.355, P=0.72 ;$ Ctrl: $1.30 \% \pm 0.23 \% ; C a_{\mathrm{V}} 3.2 \mathrm{ct}: 1.25 \% \pm$ $0.20 \% ; n=14$ from eight animals, $Z=-0.157, P=0.88)$; for $\Delta[\mathrm{Ca}]_{\mathrm{bAP}}$ in spines of CA1 neurons in acute slices bathed in solution containing a cocktail of $1 \mu$ MCTX-MVIIC, $0.3 \mu$ M SNX-482, and $10 \mu$ Mimodipine (Ctrl: $4.79 \% \pm 0.32 \%$; wild type: $4.88 \% \pm 0.48 \%$; $n=18$ from 10 animals, $Z=0.118, P=0.91$; Ctrl: $5.58 \% \pm 0.59 \%$; C456S: $6.94 \% \pm 0.63 \% ; n=16$ from 11 animals, $Z=2.793, P<0.01$; Ctrl: $5.19 \% \pm 0.54 \%$; $\mathrm{Ca}_{\mathrm{V}} 3.2 \mathrm{ct}: 1.39 \% \pm 0.21 \% ; n=18$ from eight animals, $\left.Z=3.724, P<0.0005\right)$ and in parent dendrites of CA1 neurons cultured in normal medium and bathed in normal solution (Ctrl: $2.01 \% \pm 0.14 \%$; wild type: $2.03 \% \pm 0.21 \% ; n=17$ from eight animals, $Z=-0.071, P=0.94 ; \mathrm{Ctrl}$ : $2.03 \% \pm 0.16 \%$; C456S: $2.18 \% \pm 0.19 \% ; n=20$ from 16 animals, $Z=0.684, P=0.49$; Ctrl: $2.60 \% \pm 0.23 \% ; C a_{\mathrm{V}} 3.2 \mathrm{ct}: 2.59 \% \pm 0.18 \% ; n=18$ from 12 animals, $Z=0.174, P=0.86$ ), cultured in normal medium and bathed in solution containing $1 \mu \mathrm{M}$ TTA-P2 (Ctrl: $1.01 \% \pm 0.08 \%$; C456S: $0.99 \% \pm 0.12 \% ; n=15$ from nine animals, $Z=-0.256, P=0.80 ;$ Ctrl: $1.62 \% \pm 0.17 \%$; Cav3.2ct: $1.53 \% \pm 0.22 \% ; n=14$ from eight animals, $Z=-0.282, P=0.78)$, or cultured in normal medium and bathed in solution containing $50 \mu \mathrm{M} \mathrm{Ni}{ }^{2+}\left(\mathrm{Ctrl}^{2} 1.49 \% \pm 0.14 \%\right.$; C456S: $1.43 \% \pm 0.16 \% ; n=17$ from seven animals, $Z=-1.018, P=0.31$; Ctrl: $1.41 \% \pm 0.22 \%$; Ca $3.2 \mathrm{ct}: 1.40 \% \pm 0.25 \% ; n=14$ from eight animals, $Z=-0.126, P=0.90)$; and for $\Delta[\mathrm{Ca}]_{\mathrm{bAP}}$ in parent dendrites of CA1 neurons in acute slices bathed in solution containing a cocktail of $1 \mu$ M CTX-MVIIC, $0.3 \mu$ M SNX-482, and $10 \mu$ M nimodipine (Ctrl: $5.11 \% \pm 0.21 \%$; wild type: $5.11 \% \pm 0.33 \%$; $n=18$ from 10 animals, $Z=-0.610, P=0.54$; Ctrl: $5.22 \% \pm 0.65 \%$; C456S: $5.76 \% \pm 0.64 \% ; n=16$ from 11 animals, $Z=1.534, P=0.13 ;$ Ctrl: $4.86 \% \pm 0.45 \%$; $\mathrm{Ca}_{\mathrm{V}} 3.2 \mathrm{ct}$ : $4.54 \% \pm 0.41 \% ; n=18$ from eight animals, $\left.Z=-0.947, P=0.34\right)$. (D) Line scan images and quantified traces show successes and failures of $\Delta[\mathrm{Ca}]_{\mathrm{bAP}}$ in spines. Note the successes of $\Delta[\mathrm{Ca}]_{\mathrm{bAP}}$ in the parent dendrites. $(E)$ Values of open probability $(\mathrm{Ctrl}: 0.50 \pm$ 0.06; wild type: $0.51 \pm 0.04 ; n=7$ from four animals, $Z=-0.169, P=0.87$; Ctrl: $0.50 \pm 0.06$; C456S: $0.67 \pm 0.06 ; n=6$ from four animals, $Z$ $=2.201, P<0.05$ ) and channel number (Ctrl: $3.5 \pm 0.6$; wild type: $3.3 \pm 0.4 ; n=18$ from 10 animals, $Z=0.032, P=0.98$; Ctrl: $3.3 \pm 0.5$; C456S: $3.2 \pm 0.7 ; n=16$ from 11 animals, $Z=-0.170, P=0.87$ ) of calcium channels in spines. $(F)$ Relationship between the ratio of the squared coefficients of variance of the trial-to-trail fluctuation of channel close and ratio of the mean amplitudes of channel close in hCa 3.2 (WT)-GFP-expressing ( $n=18$ from 10 animals) or hCa 3.2 (C456S)-GFP-expressing ( $n=16$ from 11 animals) and nonexpressing (Ctrl) rat CA1 neurons. The squares indicate the averages. The lines are predictions for changes in open probability of calcium channels (yellow; $[$ thin $] p_{\mathrm{Ctrl}}=0.3$; $[$ medium $] p_{\mathrm{Ctrl}}=0.5$; [thick $\left.] p_{\mathrm{Ctrl}}=0.7\right)$, number of calcium channels (red), and changes in calcium transient per opening (black). 
GFP-expressing neurons had the same $p$ and $N$ compared with neighboring control nonexpressing neurons $(n=6)$. We also analyzed calcium transients at synapses of $\mathrm{Ca}_{\mathrm{V}} 3.2 \mathrm{ct}-\mathrm{GFP}$-expressing neurons. Consistent with the functional blockade of the majority of endogenous $\mathrm{Ca}_{\mathrm{V}} 3.2$ channels by $\mathrm{Ca}_{\mathrm{V}} 3.2 \mathrm{ct}-\mathrm{GFP}$ (Fig. 5C), bAPs failed to trigger any $\mathrm{Ca}^{2+}$ transients in $\sim 45 \%$ of spines of $\mathrm{Ca}_{\mathrm{v}} 3.2 \mathrm{ct}$-GFPexpressing neurons ( $n=8$ out of 18$)$. The results were suggestive of a reduction of $N$ to zero (and/or $p$ to zero, although less likely) in these spines, albeit this precluded us from making an adequate estimation of the average $N$ and $p$ in the spines of $\mathrm{Ca}_{\mathrm{V}} 3$.2ct-GFP-expressing neurons using the fluctuation analysis. Together, the analysis suggests that overexpression of recombinant $\mathrm{hCa}_{\mathrm{v}} 3.2$ proteins results in replacement of endogenous calcium channels with equal amounts of recombinant channels at synapses but that $\mathrm{hCa}_{\mathrm{v}} 3.2(\mathrm{C} 456 \mathrm{~S})$ mutant channels open with an increased probability.

We also analyzed $\mathrm{Ca}^{2+}$ transients at single spines using a second approach that does not require counting the failure of $\Delta[\mathrm{Ca}]_{\mathrm{bAP}}$, which can be very low in some spines, and thus allowed the analysis to include all data points (Yasuda et al. 2003). We plotted the ratio of the squared coefficients of variance of the trial-to-trial fluctuation versus the ratio of mean amplitude of fluorescence in all nearby spine pairs of expressing and neighboring nonexpressing CA1 neuron pairs (Fig. 5F). The plot shows that enhanced calcium influx in the spines of neurons expressing hCa $3.2(\mathrm{C} 456 \mathrm{~S})$-GFP was quantitatively consistent with an increase in $p$ but no change in $N$ and calcium influx per opening $q$. Moreover, the results indicate that no change in calcium influx in the spines of neurons expressing hCa $3.2(\mathrm{WT})$-GFP was quantitatively consistent with no change in $p, N$, and $q$ (Fig. $5 \mathrm{~F})$. Finally, we virally expressed $\mathrm{hCa}_{\mathrm{V}} 3$.2-GFP with an additional HA tag in its extracellular domain (hCa 3 3.2-HA-GFP) in cortical L5 pyramidal neurons in vivo and then processed the tissues for anti-HA immunohistochemistry in a nonpermeabilized condition. Both hCav3.2(C456S)-HA-GFP and hCav3.2 (WT)-HA-GFP appeared in dendrites, with some delivered to the surface in spines. Quantitative analysis showed no difference in anti-HA Texas red immunofluorescence intensity at the spines of neurons expressing $\mathrm{hCa}_{\mathrm{v}} 3.2$ (C456S)-HA-GFP and hCa 3 3.2(WT)-HA-GFP (Supplemental Fig. S8), suggesting the same synaptic surface expression of hCav3.2(C456S)-HA-GFP and hCav3.2(WT)-HAGFP channels. Collectively, these results consistently support the conclusion that human CAE-linked Cav3.2 (C456S) mutant channels enhance synaptic calcium influx by replacing endogenous calcium channels with higher open probability mutant channels without changing calcium influx per opening.

\section{CAE-linked hCav3.2(C456S) mutant channels induce absence-like epilepsy}

To test whether CAE-linked gain-of-function mutations on human $\mathrm{Ca}_{\mathrm{V}} 3.2$ channels may promote seizures associated with absence epilepsy, we virally expressed recombinant hCav3.2-GFP in the rat barrel cortex, one of the primary sites known to initiate absence epilepsy (Steriade 2005; Huguenard and McCormick 2007). After 18 h of expression, we simultaneously monitored the animal's electroencephalography (EEG) with a wireless transmitter and monitored its behavior with a video camera (Fig. 6A). We found that $>60 \%$ of animals expressing $\mathrm{hCa}_{\mathrm{V}} 3.2$ (C456S)-GFP exhibited 2- to 4-Hz SWDs (Fig. 6B,C), characteristic of CAE patients (Snead 1995; Chen et al. 2003). On average, animals expressing $\mathrm{hCa}_{\mathrm{v}} 3.2(\mathrm{C} 456 \mathrm{~S})$-GFP were approximately fourfold to sixfold more likely to have 2- to 4-Hz SWDs and generated 2- to 4-Hz SWDs approximately sixfold to eightfold more frequently compared with animals expressing hCav3.2(WT)-GFP or GFP alone (Fig. 6B,C). Animals that had sham surgeries displayed no 2- to 4-Hz SWDs during the recording period. Several animals expressing hCav3.2(C456S)-GFP exhibited long and robust epileptic activity that lasted $\sim 20-40$ sec and was accompanied by behavioral arrests typical of absence seizures $(n=6)$ (Fig. 6B; Supplemental Movie S1). None of the animals expressing hCav3.2(WT)-GFP or GFP alone or animals with sham surgery displayed any absence-like behavioral arrest or seizure (see Supplemental Movie S2). These results indicate that the expression of hCav3.2(C456S) mutant proteins enhances the susceptibility of absence-like epilepsy.

Approximately $50 \%$ of CAE patients do not respond to ethosuximide, an effective T-type calcium channel antagonist and first-line drug used to treat absence epilepsy (Coulter et al. 1989; Huguenard and Prince 1994), and many of the nonresponsive patients have mutations in $\mathrm{Ca}_{\mathrm{v}} 3.2$ calcium channels (Glauser et al. 2010). We speculated that the absence epilepsy in these patients may result from the $\mathrm{Ca}_{\mathrm{v}} 3.2$ channel mutation-induced potentiation of glutamatergic transmission and thus renders the patients to be nonresponsive to T-type calcium channel antagonists once the alteration in glutamatergic transmission has taken place. To test this idea, we administered T-type channel and/or glutamatergic receptor antagonists intraperitoneally in animals expressing hCa $3.2(\mathrm{C} 456 \mathrm{~S})$ GFP prior to EEG and behavior examination (Fig. 6B,C). Administration of a single dose of TTA-P2 in animals after $18 \mathrm{~h}$ of expression of $\mathrm{hCa}_{\mathrm{V}} 3.2$ (C456S)-GFP had no effect on the occurrence of 2- to $4-\mathrm{Hz}$ SWDs. To validate whether the $\mathrm{hCa}_{\mathrm{V}} 3.2(\mathrm{C} 456 \mathrm{~S})$-mediated glutamatergic potentiation is responsible for SWDs, we administered TTA-P2 in animals every $4 \mathrm{~h}$ (four doses total) during the expression of hCav3.2(C456S)-GFP to prevent the hCav3.2(C456S)-induced potentiation of glutamatergic transmission. This dosing paradigm significantly depressed the occurrence of 2- to 4-Hz SWDs in animals expressing $\mathrm{hCa}_{\mathrm{v}} 3.2$ (C456S)-GFP (Fig. 6B,C). Consistent with the proposed epileptogenic mechanism involved in the potentiated glutamatergic transmission, we found that the four-dose, but not one-dose, TTA-P2 administration paradigm blocked the $\mathrm{hCa}_{\mathrm{v}} 3.2(\mathrm{C} 456 \mathrm{~S})$-enhanced glutamatergic transmission in cortical L5 pyramidal neurons (Supplemental Fig. S9). On the other hand, administration of one dose of the drug cocktail of MK 801, an NMDA-R antagonist, and GYKI 52466, an AMPA-R antagonist, in animals after $18 \mathrm{~h}$ of expression of $\mathrm{hCa}_{\mathrm{V}} 3.2$ (C456S)-GFP was sufficient 
A
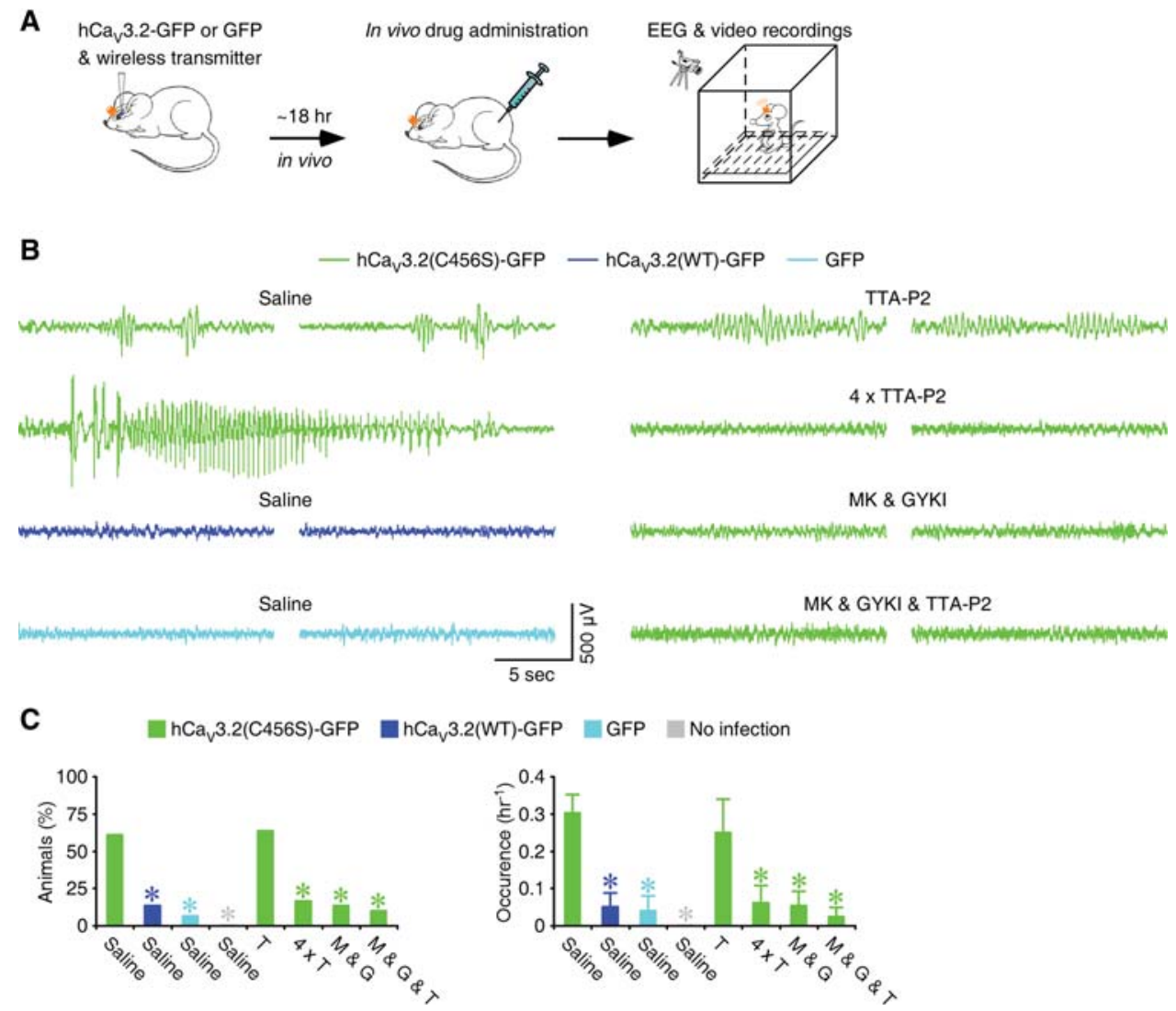

Figure 6. Human CAE-linked $\mathrm{Ca}_{\mathrm{V}} 3.2(\mathrm{C} 456 \mathrm{~S})$ mutant channels induce SWDs and absence-like epilepsy. (A) Schematic drawing outlining in vivo experimental design. (B) Examples of EEG traces recorded from hCa $3.2(\mathrm{C} 456 \mathrm{~S})$-GFP-expressing, hCa 3.2 (WT)-GFP-expressing, or GFP-alone-expressing animals without drug application or hCav3.2(C456S)-GFP-expressing animals with application of TTA-P2 only (one or four doses), MK 801 and GYKI 52466, or MK 801 and GYKI 52466 and TTA-P2 (see Supplemental Movies S1-S3 for more examples). (C) Values for the percentage of animals manifesting SWDs in $\mathrm{hCa}_{\mathrm{V}} 3.2(\mathrm{WT})$-GFP-expressing, GFP-expressing, and uninfected animals without drug application (wild type: $13.3 \% ; n=15$ animals, $\chi^{2}=10.0, P<0.01$; GFP: $6.7 \% ; n=15$ animals, $\chi^{2}=13.0, P<0.001$; no infection: $0.0 \% ; n=13$ animals, $\left.\chi^{2}=14.8, P<0.001\right)$ or hCav3.2(C456S)-GFP-expressing animals with drug application (TTA-P2: 63.6\%; $n=11$ animals, $\chi^{2}=0.03, P=0.87 ; 4 \times$ TTA-P2: $16.7 \% ; n=12$ animals, $\chi^{2}=7.3, P<0.01 ;$ MK 801 and GYKI 52466: $13.3 \% ; n=15$ animals, $\chi^{2}=10.0, P$ $<0.01$; MK 801 and GYKI 52466 and TTA-P2: $10.0 \% ; n=10$ animals, $\chi^{2}=8.36, P<0.01$ ) compared with hCa $3.2(\mathrm{C} 456 \mathrm{~S}$ )-GFP-expressing animals (C456S: $61.0 \% ; n=41$ animals) and for average occurrence of SWDs in hCav3.2(WT)-GFP-expressing, GFP-expressing, and uninfected animals without drug application (wild type: $0.052 \mathrm{~h}^{-1} \pm 0.037 \mathrm{~h}^{-1} ; n=15$ animals, $U=450.5, P<0.01 ; \mathrm{GFP}: 0.040 \mathrm{~h}^{-1} \pm 0.040 \mathrm{~h}^{-1} ; n$ $=15$ animals, $U=463.0, P<0.005$; no infection: $0.000 \mathrm{~h}^{-1} \pm 0.000 \mathrm{~h}^{-1} ; n=13$ animals, $\left.U=422.5, P<0.005\right)$ or hCa $3.2(\mathrm{C} 456 \mathrm{~S})$-GFP-expressing animals with drug application (TTA-P2: $0.250 \mathrm{~h}^{-1} \pm 0.089 \mathrm{~h}^{-1} ; n=11$ animals, $U=245.5, P=0.66 ; 4 \times \mathrm{TTA}-\mathrm{P} 2: 0.063 \mathrm{~h}^{-1} \pm$ $0.045 \mathrm{~h}^{-1} ; n=12$ animals, $U=357.5, P<0.05 ;$ MK 801 and GYKI 52466: $0.053 \mathrm{~h}^{-1} \pm 0.039 \mathrm{~h}^{-1} ; n=15$ animals, $U=446.5, P<0.01 ; \mathrm{MK}$ 801 and GYKI 52466 and TTA-P2: $0.025 \mathrm{~h}^{-1} \pm 0.025 \mathrm{~h}^{-1} ; n=10$ animals, $U=313.0, P<0.01$ ) compared with hCav3.2(C456S)-GFP-expressing animals (C456S: $0.303 \mathrm{~h}^{-1} \pm 0.050 \mathrm{~h}^{-1} ; n=41$ animals). Asterisks indicate statistical significance $\left(P<0.05, \chi^{2}\right.$ tests for the left panel, and Mann-Whitney tests for the right panel).

to significantly depress the occurrence of 2- to 4-Hz SWDs. Adding additional TTA-P2 in the glutamatergic antagonist drug cocktail only slightly improved the ameliorating effect on the occurrence of 2- to 4-Hz SWDs. None of the animals expressing hCav3.2(C456S)-GFP that were administrated with the glutamatergic antagonist drug cocktail or glutamatergic antagonist and T-type calcium channel antagonist drug cocktail displayed any absencelike behavioral arrest or seizure (see Supplemental Movie S3). These results lead us to conclude that hCav3.2 (C456S) mutant channels can increase the susceptibility of absence-like epilepsy by potentiating glutamatergic transmission.

\section{Discussion}

In this study, we investigated the physiological and pathological functions of Cav3.2 T-type low-threshold calcium channels in multiple distinct types of central neurons. Our results indicate that the general function of $\mathrm{Ca}_{\mathrm{v}} 3.2$ channels is to control NMDA-R-mediated transmission at central synapses, and dysregulation of Cav3.2 channels enhances susceptibility for human CAE.

\section{Physiological function of $\mathrm{Ca}_{V} 3.2$ channels}

$\mathrm{Ca}_{\mathrm{v}} 3.1, \mathrm{Ca}_{\mathrm{v}} 3.2$, and $\mathrm{Ca}_{\mathrm{v}} 3.3$ calcium channels are mainly expressed in the somatodendritic compartments in 
various neurons throughout the brain (Catterall 2011; Cheong and Shin 2013; Simms and Zamponi 2014). Both the $\mathrm{Ca}_{\mathrm{V}} 3.1$ and $\mathrm{Ca}_{\mathrm{V}} 3.3$ channels contribute to the lowthreshold calcium currents in central neurons (Kim et al. 2001; Astori et al. 2011; Lee et al. 2014a). These low-threshold calcium currents can promote burst synchronization with low-threshold calcium spikes and calcium-dependent potassium conductance and potentiate synaptic AMPA-R-mediated transmission with depolarization (Catterall 2011; Cheong and Shin 2013; Simms and Zamponi 2014). In contrast, $\mathrm{Ca}_{\mathrm{V}} 3.2$ channels are much less studied due in part to their relatively lower expression levels. One recent study reported that, in cultured hippocampal cells, overexpression of wild-type and gain-of-function mutant $\mathrm{Ca}_{\mathrm{v}} 3.2$ channels increased the surface expression and promoted low-threshold calcium spiking (Eckle et al. 2014). However, whether the findings hold in physiological conditions is uncertain because major cell signaling pathways are altered, and protein trafficking is thus frequently dysregulated in cultured cells. More importantly, the regulation and general function of endogenous $\mathrm{Ca}_{\mathrm{V}} 3.2$ channels in central neurons remains unclear. In this study, we examined the regulation and function of $\mathrm{Ca}_{\mathrm{v}} 3.2$ channels in multiple distinct types of central neurons in intact circuits and intact brains. We discovered that, in contrast to $\mathrm{Ca}_{\mathrm{V}} 3.1$ and $\mathrm{Ca}_{\mathrm{V}} 3.3$ channels, which are essential for generating low-threshold calcium spikes (Kim et al. 2001; Astori et al. 2011; Lee et al. 2014a), Cav3.2 channels did not modulate membrane properties or contribute to low-threshold calcium spikes, presumably due to the relatively restricted expression of only a small number of functional $\mathrm{Ca}_{\mathrm{V}} 3.2$ channels at the synapses in central neurons (Fig. 5). Instead, our results indicate that $\mathrm{Ca}_{\mathrm{v}} 3.2$ channels function to control the strength of NMDA-R-mediated transmission at the synapses. Interestingly, our data show that functional $\mathrm{Ca}_{\mathrm{V}} 3.2$ channels contribute to at least $\sim 75 \%$ of the lowthreshold calcium channel-mediated local calcium influx at the synapses and perhaps a smaller amount of calcium influx in dendrites (Fig. 5C). These results indicate that functional $\mathrm{Ca}_{\mathrm{v}} 3.2$ channels are primarily expressed at the synapses, consistent with a recent anatomical report (Francois et al. 2015). It remains to be determined whether $\mathrm{Ca}_{\mathrm{v}} 3.2$ channels in dendrites, which mediate a small amount (although an insignificant amount in this study) of calcium influx, may be responsible for controlling extrasynaptic NMDA-R-mediated transmission in central neurons.

The profound interest in the regulation of NMDA-Rmediated transmission stems from the fact that NMDA transmission contributes to fundamental neural functions, such as synaptic integration and amplification (Lavzin et al. 2012; Smith et al. 2013; Augustinaite et al. 2014; Grienberger et al. 2014; Palmer et al. 2014; Crandall et al. 2015), synaptic plasticity of AMPA-R-mediated transmission (Kessels and Malinow 2009; Stornetta and Zhu 2011; Huganir and Nicoll 2013), and behavior adaption (Cichon and Gan 2015). It is generally believed that synaptic trafficking of NMDA-Rs is more closely regulated than that of AMPA-Rs, particularly at mature synapses, and dysregulation of NMDA-R-mediated transmission has been implicated in a number of neurological, mental, and psychiatric disorders, including addiction, Alzheimer's disease, autism, depression, pathological pain, and schizophrenia (Lau and Zukin 2007; Russo et al. 2010; Hunt and Castillo 2012; Paoletti et al. 2013; Monteggia and Zarate 2015). Consistent with this idea, we show here that the numbers of functional $\mathrm{Ca}_{\mathrm{v}} 3.2$ calcium channels, the regulators of NMDA transmission, are tightly regulated at the synapses; newly expressed $\mathrm{Ca}_{\mathrm{V}} 3.2$ channels only replace existing $\mathrm{Ca}_{\mathrm{v}} 3.2$ channels at the synapses in central neurons to maintain a constant number of synaptic $\mathrm{Ca}_{\mathrm{v}} 3.2$ channels. The tight regulation of functional $\mathrm{Ca}_{\mathrm{v}} 3.2$ channels provides a mechanism for maintaining the relatively stable numbers of NMDA-Rs at the synapses. Our analysis reveals that the amount of $\mathrm{Ca}_{\mathrm{v}} 3.2$ channel-mediated calcium influx at the synapses plays a central role in controlling the strength of NMDA transmission via the regulation of synaptic expression of NMDA-Rs. We further show that synaptic activity activates $\mathrm{Ca}_{\mathrm{v}} 3.2$ channels to regulate NMDA transmission strength at the synapses (Supplemental Fig. S7), thereby extending the previous work that synaptic activity activates T-type currents (Magee and Johnston 1997). By analogy, we speculate that certain signaling molecules, including G-protein-coupled receptors, which can modulate the activity of $\mathrm{Ca}_{\mathrm{V}} 3.2$ channels (Yasuda et al. 2003; DePuy et al. 2006; Yao et al. 2006), may also mold synaptic NMDA responses.

How exactly postsynaptic $\mathrm{Ca}_{\mathrm{v}} 3.2$ channel-mediated calcium transients signal synaptic trafficking of NMDA-Rs remains largely unknown, although calcium influx at the synapses is believed to be essential for the regulation of NMDA transmission (Lau and Zukin 2007; Hunt and Castillo 2012; Paoletti et al. 2013; Cerpa et al. 2015). In addition, recent findings have implicated that several molecules may relay signaling downstream from synaptic calcium influx to regulate NMDA transmission (Setou et al. 2000; Jeyifous et al. 2009; Udagawa et al. 2012; Plattner et al. 2014; Wang and Zhu 2014; Wei et al. 2014; Sheng et al. 2015). Some of the signaling molecules (e.g., PKA, PKC, JNK, Fyn, and Cdk5) could potentially control phosphorylation of transcription and translation factors, sorting, transporting, and scaffolding proteins as well as NMDA-Rs to signal synaptic delivery and/or removal of NMDA-Rs. Obviously, compared with synaptic regulation of AMPA-Rs, our understanding of the dynamics of trafficking and function of NMDA-Rs has advanced much more slowly, and many questions remain unanswered (Lau and Zukin 2007; Hunt and Castillo 2012; Paoletti et al. 2013). Our discovery of the powerful effect of $\mathrm{Ca}_{\mathrm{v}} 3.2$ channels on NMDA transmission provides a technically feasible approach to address these fundamental questions in the near future. This study also identifies $\mathrm{Ca}_{\mathrm{V}} 3.2$ channels as a new potential drug target for treating the disorders resulting from the dysregulation of NMDA transmission.

\section{Pathological function of $C a_{V} 3.2$ channels}

Human CAE is the most common form of pediatric epilepsy (Tenney and Glauser 2013). A number of absence 
epilepsy animal models have been reported. However, with the exception of the $\gamma$-butyrolactone-based pharmacological model (Schofield et al. 2009; Zaman et al. 2011), all of the commonly used animal models, including genetic animal models, failed to produce the $\sim 2-$ to $4-\mathrm{Hz}$ SWDs characteristic of CAE patients (Snead 1995; Chen et al. 2003; Tenney and Glauser 2013). Therefore, it is still challenging to define the genetic nature and epileptogenic mechanism of human CAE. Here, we showed that expression of $\mathrm{hCa}_{\mathrm{v}} 3.2(\mathrm{C} 456 \mathrm{~S})$ alone in rats was sufficient to markedly enhance the incidence of $\sim 2$ - to $4-\mathrm{Hz}$ SWDs and behavioral arrests or seizures closely resembling patients with CAE (Snead 1995; Chen et al. 2003; Tenney and Glauser 2013). These results provide the first evidence indicating $C A C N A 1 H$ to be a primary gene responsible for CAE susceptibility. Our analysis shows that expression of $\mathrm{hCa}_{\mathrm{V}} 3.2$ (C456S) results in the replacement of endogenous $\mathrm{Ca}_{\mathrm{V}} 3.2$ channels with higher open probability mutant channels without altering calcium influx per opening. This replacement increases the local calcium influx at synapses and leads to the up-regulation of glutamatergic transmission and enhancement of the susceptibility of absence-like epilepsy. These findings reveal a new epileptogenic mechanism for CAE and explain the clinical conundrum that CAE patients carrying $\mathrm{Ca}_{\mathrm{v}} 3.2$ channel mutations do not respond to ethosuximide.

As a fairly common form of generalized seizure, the network mechanisms of SWDs have been extensively investigated for more than seven decades (Avoli 2012; Luttjohann and van Luijtelaar 2015). Accumulating evidence indicates that SWDs are generated within the corticothalamocortical circuitry and that the dynamic interaction of local microcircuits within this neuronal network leads to the "full-blown" SWDs associated with absence epilepsy (McCormick and Contreras 2001; Steriade 2005; Huguenard and McCormick 2007; Luttjohann and van Luijtelaar 2015). The very early studies of absence epilepsy (also known as petit mal epilepsy) reported that SWDs, as in human absence epilepsy, could initiate and sustain after a brief electric stimulation in the thalamus in animals (Lewy and Gammon 1940; Lindsley et al. 1949). Later, EEG recordings in humans showed that SWDs occurred in the thalamus prior to the cortex (Williams 1953). These results suggest a possible thalamic origin of SWDs. In the following 50 years, results supporting either the cortical or thalamic origin of SWDs have been reported (Avoli 2012). In the most recent studies, investigators employed the simultaneous EEG and/or functional magnetic resonance imaging (fMRI) recordings at multiple cortical and thalamic sites and saw the precursor activity in specific cortical areas prior to SWD onset in animal models (Meeren et al. 2002; David et al. 2008) as well as in human patients (Tyvaert et al. 2009; Bai et al. 2010). These findings provide the most compelling evidence supporting that the cortex is actually the initiator of SWDs, although technical limitations prevented the simultaneous monitoring of every thalamic and cortical area or subareas potentially involved in SWDs in these studies (Luttjohann and van Luijtelaar 2015). Here, we introduced an alternative genet- ic approach that may address network mechanisms in a complementary way. We showed that the selective expression of human CAE-linked $\mathrm{Ca}_{\mathrm{v}} 3.2$ (C456S) mutant proteins in the rat barrel cortex is sufficient to enhance the susceptibility of 2- to 4-Hz SWDs characteristic of human CAE patients. The results validate the possibility of making CAE-linked genetic modifications in one or multiple thalamic and/or cortical areas in animal models and thus open a new avenue to dissect the contributions of local microcircuits in the thalamic nuclei and/or cortical areas in the generation, maintenance, and termination of SWDs. For example, it would be interesting and feasible to test whether expression of $\mathrm{hCa}_{\mathrm{v}} 3.2(\mathrm{C} 456 \mathrm{~S})$ in TRN alone may induce the ictogenic process and whether, in both TRN and cortical areas, as likely occurs in the human condition, it may synergistically reduce the ictogenic threshold. Together, the complementary research approaches will facilitate delineation of the genetic, cellular, and neuronal network mechanisms of SWDs associated with human CAE, which are essential for developing new effective therapeutic options to treat this neurological disorder (Maheshwari and Noebels 2014; Paz and Huguenard 2015).

\section{Materials and methods}

\section{Cultured and acute slice preparation}

Organotypic hippocampal cultured slices were prepared from postnatal 6- to 7-d-old (P6-P7) male and female Sprague Dawley rats, wild-type mice, and $\mathrm{Ca}_{\mathrm{V}} 3.2$ knockout (Orestes et al. 2009) mice bred congenically on the C57BL/6 background, following our previous studies (Qin et al. 2005; Lim et al. 2014). All procedures for animal surgery and maintenance were performed following protocols approved by the animal care and use committee of the University of Virginia and in accordance with National Institutes of Health guidelines. The hippocampi were dissected out in ice-cold HEPES-buffered Hanks' solution (pH 7.35) under sterile conditions, sectioned into $400-\mu \mathrm{m}$ slices on a tissue chopper, and explanted onto a Millicell-CM membrane $(0.4-\mu \mathrm{m}$ pore size; Millipore). The membranes were then placed in $750 \mu \mathrm{L}$ of MEM culture medium containing $30 \mathrm{mM}$ HEPES, $20 \%$ heat-inactivated horse serum, $1.4 \mathrm{mM}$ glutamine, $16.25 \mathrm{mM}$ D-glucose, $5 \mathrm{mM} \mathrm{NaHCO}_{3}, 1 \mathrm{mM} \mathrm{CaCl}, 2 \mathrm{mM} \mathrm{MgSO}_{4}, 1 \mathrm{mg} / \mathrm{mL}$ insulin, and $0.012 \%$ ascorbic acid (pH 7.28, osmolarity 320). Cultured slices were maintained at $35^{\circ} \mathrm{C}$ in a humidified incubator (ambient air enriched with $5 \% \mathrm{CO}_{2}$ ). Acute thalamic, cortical, and hippocampal slices were prepared from P14-P26 male and female Sprague Dawley rats. Animals were deeply anesthetized by xylazine-ketamine and decapitated. The brain containing the thalamus, barrel cortex, and/or hippocampus was quickly removed and placed into cold $\left(0^{\circ} \mathrm{C}-4^{\circ} \mathrm{C}\right)$ oxygenated physiological solution containing $125 \mathrm{mM} \mathrm{NaCl}, 2.5 \mathrm{mM} \mathrm{KCl}, 1.25 \mathrm{mM} \mathrm{NaH}_{2} \mathrm{PO}_{4}, 25$ $\mathrm{mM} \mathrm{NaHCO}_{3}, 1 \mathrm{mM} \mathrm{MgCl} 2,25 \mathrm{mM}$ dextrose, and $2 \mathrm{mM}$ $\mathrm{CaCl}_{2}$ (pH 7.4). To obtain the thalamic slices containing the TRN, horizontal slices $350 \mu \mathrm{m}$ thick were cut from the brain blocks with their ventral surface glued down to the cutting chamber of a microslicer. For acute cortical preparations, parasagittal slices $350 \mu \mathrm{m}$ thick were cut from the brain blocks. For acute hippocampal preparations, parasagittal slices $350 \mu \mathrm{m}$ thick were cut from the brain blocks. These slices were kept at $37.0^{\circ} \mathrm{C}$ $\pm 0.5^{\circ} \mathrm{C}$ in oxygenated physiological solution for $\sim 0.5-1 \mathrm{~h}$ before recording. 


\section{Constructs and recombinant protein expression}

To avoid the potential compensatory and other nonspecific effects that may be associated with chronic overexpression of $\mathrm{Ca}_{\mathrm{V}}$. 3.2 channels (Simms and Zamponi 2014) and long-lasting changes in glutamatergic transmission (Kessels and Malinow 2009; Stornetta and Zhu 2011), the rapid Sindbis and lentiviral expression systems were used in all experiments. Because the regulation of protein trafficking in cultured neurons can be very different from those in cultured slices and intact brains (Kessels and Malinow 2009; Stornetta and Zhu 2011), all expressions were made in neurons in cultured slices and intact brains. GFP- and/or HAtagged human $\mathrm{Ca}_{\mathrm{V}} 3.2$ wild-type constructs (Supplemental Fig. $\mathrm{S} 10)-\mathrm{hCa}_{\mathrm{V}} 3.2(\mathrm{WT})$-GFP and $\mathrm{hCa}_{\mathrm{V}} 3.2$ (WT)-HA-GFP - were gifts from Dr. Emmanuel Bourinet (Dubel et al. 2004). Mutant $\mathrm{C} 456 \rightarrow \mathrm{S}$ constructs were generated from $\mathrm{hCa}_{\mathrm{v}} 3.2$ (WT)-GFP and $\mathrm{hCa}_{\mathrm{V}} 3.2$ (WT)-HA-GFP using Quick Change XL site-directed mutagenesis kit (Stratagene). The wild-type and mutant hCav 3.2 constructs were subcloned into a Sindbis viral construct. The C terminus of rat $\mathrm{Ca}_{\mathrm{V}} 3.2$ was first subcloned into pEGFP-C1 or pRFP-C1 (Clontech Laboratories) and then into the Sindbis viral construct. ChR2-mCherry was subcloned into Sindbis and lentiviral constructs. In some experiments, GFP was replaced with CFP, mCherry, or mOrange (gifts from Dr. Roger Tsien). For in vitro expression, neurons were infected after $6-14 \mathrm{~d}$ in culture. For in vivo expression, unless stated otherwise, P13-P25 animals were initially anesthetized with an intraperitoneal (i.p.) injection of $10 \mathrm{mg} / \mathrm{kg}$ ketamine and $2 \mathrm{mg} / \mathrm{kg}$ xylaxine and then placed in a stereotaxic frame with a hole of $\sim 1 \mathrm{~mm} \times 1 \mathrm{~mm}$ drilled above the right barrel cortex. A glass pipette was used to penetrate into the thalamic VB, TRN, barrel cortex, and/or hippocampus according to stereotaxic coordinates, and $\sim 50 \mathrm{~nL}$ of viral solution was delivered by pressure injection. The injection produced the restricted expression of ChR2 in either the VB or the barrel cortex (Supplemental Fig. S6). The titer of the viral solution was adjusted for both in vitro and in vivo electrophysiology experiments to express $\mathrm{Ca}_{\mathrm{v}} 3.2$ constructs in only a few neurons (typically, one to five neurons per slice/brain) (Supplemental Fig. S1A). For behavioral experiments, three parallel strips of $\sim 3 \mathrm{~mm} \times 0.75 \mathrm{~mm}$ were drilled above the right barrel cortex, and eight to nine injections of $\sim 6 \mu \mathrm{L}$ of high-titer viral solution were delivered in the entire barrel cortex. Experiments were typically performed at $18 \mathrm{~h} \pm$ $3 \mathrm{~h}$ after Sindbis viral infection or $72 \mathrm{~h} \pm 6 \mathrm{~h}$ after lentiviral infection.

\section{Immunostaining and immunoelectron microscopy}

Immunostaining of the HA tag was carried out as previously described (Zhu et al. 2000). To reduce the variation of immunostaining intensity, hCav3.2(WT)-HA-GFP and hCav3.2(C456S)-HAGFP were expressed in the barrel cortical L5 in the different hemispheres of the same animals, and the tissue sections containing the expressing neurons were processed simultaneously. To evaluate the surface expression of $\mathrm{hCa}_{\mathrm{v}} 3.2-\mathrm{HA}-\mathrm{GFP}$, detergents were omitted in all incubations. Antibody incubations were in $\mathrm{PBS}$ for $48 \mathrm{~h}$ at $4^{\circ} \mathrm{C}$ (primary anti-HA antibody, 1:500; Covance, 16B12) or overnight (secondary antibody and avidin-Texas red). Pre-embedding immunogold labeling was carried out following the procedures of previous studies (Erisir and Harris 2003; Kielland et al. 2009). In brief, $1 \mu \mathrm{g} / \mathrm{mL}$ rabbit anti-GluA2/3 (Millipore, AB1506) was used to detect AMPA-Rs because of the nonrectified AMPA responses seen in CA1 and L5 pyramidal neurons (Zhu 2009; Lim et al. 2014) and TRN neurons (values for rectification: $R_{\mathrm{VB} \mathrm{stim}}=1.51 \pm 0.06$ and $R_{\text {cortex stim }}=1.54 \pm 0.08 ; n=19$ from nine animals), an indicator of incorporation of GluA2 subunits in the majority of AMPA-Rs. A mouse monoclonal anti-GluN1 (Luo et al. 1997) was used to detect the obligatory GluN1 subunits of NMDA-Rs. Sample sections were rinsed in PBS and incubated with antibodies and $1 \mathrm{~nm}$ of gold-conjugated goat anti-rabbit or mouse IgG (1:50; GE Healthcare Bio-Sciences) for $2 \mathrm{~h}$ followed by citrate buffer rinse and silver intensification for $\sim 8-10 \mathrm{~min}$. Immunolabeled sections were fixed with $1 \% \mathrm{OsO}_{4}$ for $1 \mathrm{~h}$ and flat-embedded between two pieces of Aclar (Ted Pella, Inc.), and the resin was left to polymerize for $48 \mathrm{~h}$ at $60^{\circ} \mathrm{C}$. With high-titer viruses, $\sim 70 \%-85 \%$ of neurons, identified by GFP fluorescence, could be infected near the injection sites (Supplemental Fig. S11). Only the highly infected areas were excised and resectioned into 80-nm ultrathin sections using an ultramicrotome. Ultrathin sections were examined with a transmission electron microscope (Japan Electron Optic, JEOL-1010). Nonspecific immunogold labeling was low, as indicated by very low counts of silver-enhanced gold particles in presynaptic regions. The thalamic and cortical synapses of TRN neurons could be unambiguously classified into two groups based on their characteristic presynaptic terminals. Specifically, the thalamic synapses were contacted by $\mathrm{L}$ terminals that had a large terminal with loosely packed spherical vesicles and typically contained multiple mitochondria, whereas the cortical synapses were contacted by D terminals that had a small terminal with densely packed spherical vesicles and contained no or single mitochondria (Ohara 1988). We counted all silver-enhanced gold particles within $500 \mathrm{~nm}$ from the postsynaptic membrane (approximately one to six per synapse) and classified those within the concentric rings of -6.25 to 31.25 $\mathrm{nm}$ from the postsynaptic membrane into the synaptic pool and those of 31.25-106.25 nm into the deliverable pool (cf. Kielland et al. 2009).

\section{Electrophysiology}

Using our recently developed stable multiple patch clamp recording system (Jiang et al. 2013; Lee et al. 2014b; Wang et al. 2015), simultaneous and/or sequential multiple whole-cell recordings were obtained from two to five nearby infected and noninfected TRN neurons or cortical L5 or hippocampal CA1 pyramidal neurons under visual guidance using fluorescence and transmitted light illumination. For cultured slices, bath solution $\left(29^{\circ} \mathrm{C} \pm\right.$ $1.5^{\circ} \mathrm{C}$ ) contained $119 \mathrm{mM} \mathrm{NaCl}, 2.5 \mathrm{mM} \mathrm{KCl}, 4 \mathrm{mM} \mathrm{CaCl}_{2}, 4$ $\mathrm{mM} \mathrm{MgCl} 2,26 \mathrm{mM} \mathrm{NaHCO}_{3}, 1 \mathrm{mM} \mathrm{NaH} \mathrm{PO}_{4}, 11 \mathrm{mM}$ glucose, $0.1 \mathrm{mM}$ picrotoxin (PTX), $0.01 \mathrm{mM}$ bicuculline, and $0.002 \mathrm{mM} 2$ chloroadenosine $(\mathrm{pH} 7.4)$ gassed with $5 \% \mathrm{CO}_{2} / 95 \% \mathrm{O}_{2}$. For experiments in which slices were maintained in culture medium with additional $100 \mu \mathrm{M}$ DL-APV, $5 \mu \mathrm{M}$ DCKA, $50 \mu \mathrm{M} \mathrm{Ni}^{2+}, 1 \mu \mathrm{M}$ TTA$\mathrm{P} 2,10 \mathrm{mM} \mathrm{Mg}^{2+}$, or $2 \mu \mathrm{M}$ TTX, these reagents were included in the culture medium during expression but not in the bath solution during recording. For acute slices, 2-chloroadenosine was excluded; $2 \mathrm{mM} \mathrm{CaCl}_{2}$ and $1 \mathrm{mM} \mathrm{MgCl}$ were used instead in the bath solution. PTX was excluded when GABA responses were examined. Whole-cell recordings were made with up to five Axopatch-200B patch clamp amplifiers (Molecular Devices). Junction potentials were not corrected. Synaptic responses were evoked by bipolar electrodes with single voltage pulses (200 $\mu s e c$, up to $20 \mathrm{~V}$ ). Synaptic AMPA and NMDA responses at -60 $\mathrm{mV}$ and $+40 \mathrm{mV}$ were averaged over 90 trials.

\section{Two-photon imaging and optogenetics}

Two-photon imaging and electrophysiology recordings were simultaneously performed using a custom-built microscope operated by a custom-written IGOR Pro 6 program (WaveMetrics) (Wang et al. 2015). To minimize the $\mathrm{Ca}^{2+}$ signal variances resulting from the different location of synapses and loading time of 
indicators (Sabatini and Svoboda 2000; Yasuda et al. 2003), neighboring expressing and nonexpressing CA1 neuron pairs were broken in simultaneously to load $200 \mu \mathrm{M}$ green calcium-sensitive indicator Fluo-5F and $20 \mu \mathrm{M}$ red calcium-insensitive indicator Alexa 594. After $\sim 15-30 \mathrm{~min}$ of loading of indicators, fluorescence of nearby spine pairs of neighboring expressing and nonexpressing CA1 neuron pairs was simultaneously imaged with 500$\mathrm{Hz}$ line scanning that intersected both the spines and their parent dendrites. Alexa 594 and Fluo-5F were excited by a femtosecond Ti:Sapphire laser (Chameleon Ultra, Coherent) at a wavelength of $880 \mathrm{~nm}$. Calcium channels were activated by the single bAPs evoked with somatic current injections in expressing and nonexpressing neurons. Changes in fluorescence were quantified as increases in green (Fluo-5F) fluorescence from baseline divided by resting red (Alexa fluor 594) fluorescence $(\Delta \mathrm{G} / \mathrm{R})$ and averaged for $\sim 50-200$ trials. No optical fluctuation analysis of calcium channels at single spines was performed in neurons expressing $\mathrm{Ca}_{\mathrm{v}} 3.2 \mathrm{ct}$ due to no calcium transients being detected in many of the spines imaged ( $n=8$ out of 18 ). Optogenetic activation of the ChR2-expressing axonal terminals originating from VB neurons or cortical neurons in the TRN was made with a 473-nm blue laser (OBIS, Coherent). The OBIS laser was coupled to the two-photon laser light path and delivered onto the specimen using the same objective. The laser power at the specimen was set at $0.1-15 \mathrm{~mW}$, and $10-\mathrm{msec}$ light pulses were generated with a fast shutter (Uniblitz UHS1, Vincent Associates).

\section{EEG recording and behavior monitoring}

After viral expression of hCav3.2-GFP or GFP in the right side of the barrel cortex, a wireless EEG transmitter (Epoch in vivo recording system, Ripple) was implanted above the cortex of the animals (Fig. 6A; Supplemental Movie 1). EEG activity was recorded at $18 \mathrm{~h} \pm 3 \mathrm{~h}$ after surgery and viral expression, and animal behavior was simultaneously monitored by a video camera for a period of $6 \mathrm{~h} \pm 2 \mathrm{~h}$ (from approximately 12 a.m. -6 a.m.). TTA-P2 (10 mg/ $\mathrm{kg}$; supplied by Dr. Victor Uebele at Merck), $0.05 \mathrm{mg} / \mathrm{kg}$ MK 801, and/or 20 mg/kg GYKI 52466 (cf. Rajasekaran et al. 2012) were administered via i.p. injections prior to EEG and behavior recording. In some experiments, to prevent $\mathrm{Ca}_{\mathrm{v}} 3.2(\mathrm{C} 456 \mathrm{~S})$-GFP from potentiating glutamatergic synaptic transmission in expressing animals, four doses of TTA-P2 spaced by $4 \mathrm{~h}$ were administered, with the first dose of TTA-P2 administered at $4 \mathrm{~h}$ after the viral injection, considering $\sim 6-8 \mathrm{~h}$ required for viral expression of recombinant proteins. These drugs were dissolved in saline, and saline alone was used as a control. The behavioral data were analyzed blind of control and experiment groups.

\section{Statistical analysis}

Statistical results were reported as mean \pm SEM. Statistical significances of the means $(P \leq 0.05$, two-sided) were determined using Wilcoxon and Mann-Whitney rank sum nonparametric or $\chi^{2}$ tests for paired and unpaired samples, respectively.

\section{Acknowledgments}

We thank Dr. Roberto Malinow, Dr. Bernardo Sabatini, Dr. Karel Svoboda, and Dr. Robert Wong for technical advice and invaluable discussions, and members of the Zhu laboratory for comments and technical assistance. J.J.Z conceived the project. G.W., G.B., Y.C., K.A.S., P.Z., R.L.S., and J.J.Z. performed the experiments in the Zhu and Beenhakker laboratories, which are supported in part by National Institutes of Health grants
R01NS053570 (to J.J.Z.) and R01NS091452 (to J.J.Z., J.K., and M.P.B.). S.J.D., E.P.-R., T.P.S., K.D., S.M.T., and J.-H.L. provided reagents, and J.J.Z. supervised the project with input and assistance from A.E., R.L.S., S.M.T., J.K., and M.P.B. Additional support to the project is from a post-doctoral fellowship (no. 310443) from the Epilepsy Foundation (to G.W.); the National Institutes of Health predoctoral training grant fellowship in neuroscience (to K.A.S); National Institutes of Health grants R01NS067456 (to E.P.-R. and J.J.Z.), R01GM102525 (to S.M.T. and J.J.Z.), R01NS040337 (to J.K. and J.J.Z.), and R01DC010183 (to A.E.); the Howard Hughes Medical Institute (to K.D.); the National Basic Research Program of China (no. 2010CB912002 to J.-H.L.); the Natural Science Foundation of China (nos. 30730038 and 81171164 to J.-H.L.); the Canadian Institutes of Health Research (no. 10677 to T.P.S.); and a Canada Research Chair in Biotechnology and Genomics-Neurology (to T.P.S.).

\section{References}

Astori S, Wimmer RD, Prosser HM, Corti C, Corsi M, Liaudet N, Volterra A, Franken P, Adelman JP, Luthi A. 2011. The Cav3.3 calcium channel is the major sleep spindle pacemaker in thalamus. Proc Natl Acad Sci 108: 13823-13828.

Augustinaite S, Kuhn B, Helm PJ, Heggelund P. 2014. NMDA spike/plateau potentials in dendrites of thalamocortical neurons. J Neurosci 34: 10892-10905.

Avoli M. 2012. A brief history on the oscillating roles of thalamus and cortex in absence seizures. Epilepsia 53: 779-789.

Bai X, Vestal M, Berman R, Negishi M, Spann M, Vega C, Desalvo M, Novotny EJ, Constable RT, Blumenfeld H. 2010. Dynamic time course of typical childhood absence seizures: EEG, behavior, and functional magnetic resonance imaging. I Neurosci 30: 5884-5893.

Catterall WA. 2011. Voltage-gated calcium channels. Cold Spring Harb Perspect Biol 3: a003947.

Cerpa W, Latorre-Esteves E, Barria A. 2015. RoR2 functions as a noncanonical Wnt receptor that regulates NMDAR-mediated synaptic transmission. Proc Nat1 Acad Sci 112: 4797-4802.

Chen Y, Lu J, Pan H, Zhang Y, Wu H, Xu K, Liu X, Jiang Y, Bao X, Yao Z, et al. 2003. Association between genetic variation of CACNA1H and childhood absence epilepsy. Ann Neurol 54: 239-243.

Cheong E, Shin HS. 2013. T-type $\mathrm{Ca}^{2+}$ channels in normal and abnormal brain functions. Physiol Rev 93: 961-992.

Chioza B, Everett K, Aschauer H, Brouwer O, Callenbach P, Covanis A, Dulac O, Durner M, Eeg-Olofsson O, Feucht M, et al. 2006. Evaluation of CACNA1H in European patients with childhood absence epilepsy. Epilepsy Res 69: 177-181.

Cichon J, Gan WB. 2015. Branch-specific dendritic $\mathrm{Ca}^{2+}$ spikes cause persistent synaptic plasticity. Nature 520: 180-185.

Coulter DA, Huguenard JR, Prince DA. 1989. Characterization of ethosuximide reduction of low-threshold calcium current in thalamic neurons. Ann Neurol 25: 582-593.

Crandall SR, Cruikshank SJ, Connors BW. 2015. A corticothalamic switch: controlling the thalamus with dynamic synapses. Neuron 86: 768-782.

David O, Guillemain I, Saillet S, Reyt S, Deransart C, Segebarth C, Depaulis A. 2008. Identifying neural drivers with functional MRI: an electrophysiological validation. PLOS Biol 6: 2683-2697.

DePuy SD, Yao J, Hu C, McIntire W, Bidaud I, Lory P, Rastinejad F, Gonzalez C, Garrison JC, Barrett PQ. 2006. The molecular basis for T-type $\mathrm{Ca}^{2+}$ channel inhibition by $\mathrm{G}$ protein $\beta_{2} \gamma_{2}$ subunits. Proc Natl Acad Sci 103: 14590-14595. 
Dubel SJ, Altier C, Chaumont S, Lory P, Bourinet E, Nargeot J. 2004. Plasma membrane expression of T-type calcium channel a(1) subunits is modulated by high voltage-activated auxiliary subunits. J Biol Chem 279: 29263-29269.

Eckle VS, Shcheglovitov A, Vitko I, Dey D, Yap CC, Winckler B, Perez-Reyes E. 2014. Mechanisms by which a CACNA1H mutation in epilepsy patients increases seizure susceptibility. $I$ Physiol 592: 795-809.

Erisir A, Harris JL. 2003. Decline of the critical period of visual plasticity is concurrent with the reduction of NR2B subunit of the synaptic NMDA receptor in layer 4. I Neurosci 23: 5208-5218.

Francois A, Schuetter N, Laffray S, Sanguesa J, Pizzoccaro A, Dubel S, Mantilleri A, Nargeot J, Noel J, Wood JN, et al. 2015. The low-threshold calcium channel $\mathrm{Ca}_{\mathrm{V}} 3.2$ determines low-threshold mechanoreceptor function. Cell Rep 10: 730782.

Glauser TA, Cnaan A, Shinnar S, Hirtz DG, Dlugos D, Masur D, Clark PO, Capparelli EV, Adamson PC. 2010. Ethosuximide, valproic acid, and lamotrigine in childhood absence epilepsy. N Engl J Med 362: 790-799.

Grienberger C, Chen X, Konnerth A. 2014. NMDA receptordependent multidendrite $\mathrm{Ca}^{2+}$ spikes required for hippocampal burst firing in vivo. Neuron 81: 1274-1281.

Heron SE, Khosravani H, Varela D, Bladen C, Williams TC, Newman MR, Scheffer IE, Berkovic SF, Mulley JC, Zamponi GW. 2007. Extended spectrum of idiopathic generalized epilepsies associated with $C A C N A 1 H$ functional variants. Ann Neurol 62: 560-568.

Huganir RL, Nicoll RA. 2013. AMPARs and synaptic plasticity: the last 25 years. Neuron 80: 704-717.

Huguenard JR, McCormick DA. 2007. Thalamic synchrony and dynamic regulation of global forebrain oscillations. Trends Neurosci 30: 350-356.

Huguenard JR, Prince DA. 1994. Intrathalamic rhythmicity studied in vitro: nominal $\mathrm{T}$-current modulation causes robust antioscillatory effects. J Neurosci 14: 5485-5502.

Hunt DL, Castillo PE. 2012. Synaptic plasticity of NMDA receptors: mechanisms and functional implications. Curr Opin Neurobiol 22: 496-508.

Jeyifous O, Waites CL, Specht CG, Fujisawa S, Schubert M, Lin EI, Marshall J, Aoki C, de Silva T, Montgomery JM, et al. 2009. SAP97 and CASK mediate sorting of NMDA receptors through a previously unknown secretory pathway. Nat Neurosci 12: 1011-1019.

Jiang X, Wang G, Lee AJ, Stornetta RL, Zhu JJ. 2013. The organization of two new cortical interneuronal circuits. Nat Neurosci 16: 210-218.

Kessels HW, Malinow R. 2009. Synaptic AMPA receptor plasticity and behavior. Neuron 61: 340-350.

Kielland A, Bochorishvili G, Corson J, Zhang L, Rosin DL, Heggelund P, Zhu JJ. 2009. Activity patterns govern synapse-specific AMPA-R trafficking between deliverable and synaptic pools. Neuron 62: 84-101.

Kim D, Song I, Keum S, Lee T, Jeong MJ, Kim SS, McEnery MW, Shin HS. 2001. Lack of the burst firing of thalamocortical relay neurons and resistance to absence seizures in mice lacking a(1G) T-type $\mathrm{Ca}^{2+}$ channels. Neuron 31: 35-45.

Lau CG, Zukin RS. 2007. NMDA receptor trafficking in synaptic plasticity and neuropsychiatric disorders. Nat Rev Neurosci 8: 413-426.

Lavzin M, Rapoport S, Polsky A, Garion L, Schiller J. 2012. Nonlinear dendritic processing determines angular tuning of barrel cortex neurons in vivo. Nature 490: 397-401.
Lee SE, Lee J, Latchoumane C, Lee B, Oh SI, Saud ZA, Park C, Sun N, Cheong E, Chen CC, et al. 2014a. Rebound burst firing in the reticular thalamus is not essential for pharmacological absence seizures in mice. Proc Natl Acad Sci 111: 11828-11833.

Lee AJ, Wang G, Jiang X, Johnson SM, Hoang ET, Lante F, Stornetta RL, Beenhakker MP, Shen Y, Zhu J. 2014b. Canonical organization of layer 1 neuron-led cortical inhibitory and disinhibitory interneuronal circuits. Cereb Cortex doi: 10.1093/ cercor/bhu020.

Lewy FH, Gammon GD. 1940. Influence of sensory systems on spontaneous activity of cerebral cortex. I Neurophysiol 3: 388-395.

Liang J, Zhang Y, Wang J, Pan H, Wu H, Xu K, Liu X, Jiang Y, Shen $\mathrm{Y}, \mathrm{Wu} \mathrm{X}$. 2006. New variants in the CACNA1H gene identified in childhood absence epilepsy. Neurosci Lett 406: 27-32.

Lim CS, Hoang ET, Viar KE, Stornetta RL, Scott MM, Zhu JJ. 2014. Pharmacological rescue of Ras signaling, GluA1-dependent synaptic plasticity, and learning deficits in a fragile $\mathrm{X}$ model. Genes Dev 28: 273-289.

Lindsley DB, Bowden JW, Magoun HW. 1949. Effect upon the EEG of acute injury to the brain stem activating system. Electroencephalogr Clin Neurophysiol 1: 457-486.

Luo J, Wang Y, Yasuda RP, Dunah AW, Wolfe BB. 1997. The majority of N-methyl-D-aspartate receptor complexes in adult rat cerebral cortex contain at least three different subunits (NR1/ NR2A/NR2B). Mol Pharmacol 51: 79-86.

Luttjohann A, van Luijtelaar G. 2015. Dynamics of networks during absence seizure's on- and offset in rodents and man. Front Physiol 6: 16.

Magee JC, Johnston D. 1997. A synaptically controlled, associative signal for Hebbian plasticity in hippocampal neurons. Science 275: 209-213.

Maheshwari A, Noebels JL. 2014. Monogenic models of absence epilepsy: windows into the complex balance between inhibition and excitation in thalamocortical microcircuits. Prog Brain Res 213: 223-252.

McCormack SG, Stornetta RL, Zhu JJ. 2006. Synaptic AMPA receptor exchange maintains bidirectional plasticity. Neuron 50: $75-88$.

McCormick DA, Contreras D. 2001. On the cellular and network bases of epileptic seizures. Annu Rev Physiol 63: 815-846.

McRory JE, Santi CM, Hamming KS, Mezeyova J, Sutton KG, Baillie DL, Stea A, Snutch TP. 2001. Molecular and functional characterization of a family of rat brain T-type calcium channels. J Biol Chem 276: 3999-4011.

Meeren HK, Pijn JP, Van Luijtelaar EL, Coenen AM, Lopes da Silva FH. 2002. Cortical focus drives widespread corticothalamic networks during spontaneous absence seizures in rats. I Neurosci 22: 1480-1495.

Monteggia LM, Zarate C Jr. 2015. Antidepressant actions of ketamine: from molecular mechanisms to clinical practice. Curr Opin Neurobiol 30: 139-143.

Ohara PT. 1988. Synaptic organization of the thalamic reticular nucleus. J Electron Microsc Tech 10: 283-292.

Orestes P, Bojadzic D, Chow RM, Todorovic SM. 2009. Mechanisms and functional significance of inhibition of neuronal T-type calcium channels by isoflurane. Mol Pharmacol 75: 542-554.

Palmer LM, Shai AS, Reeve JE, Anderson HL, Paulsen O, Larkum ME. 2014. NMDA spikes enhance action potential generation during sensory input. Nat Neurosci 17: 383-390.

Paoletti P, Bellone C, Zhou Q. 2013. NMDA receptor subunit diversity: impact on receptor properties, synaptic plasticity and disease. Nat Rev Neurosci 14: 383-400. 
Paz JT, Huguenard JR. 2015. Microcircuits and their interactions in epilepsy: is the focus out of focus? Nat Neurosci 18: 351-359.

Plattner F, Hernandez A, Kistler TM, Pozo K, Zhong P, Yuen EY, Tan C, Hawasli AH, Cooke SF, Nishi A, et al. 2014. Memory enhancement by targeting Cdk5 regulation of NR2B. Neuron 81: 1070-1083.

Qin Y, Zhu Y, Baumgart JP, Stornetta RL, Seidenman K, Mack V, van Aelst L, Zhu JJ. 2005. State-dependent Ras signaling and AMPA receptor trafficking. Genes Dev 19: 2000-2015.

Rajasekaran K, Todorovic M, Kapur J. 2012. Calcium-permeable AMPA receptors are expressed in a rodent model of status epilepticus. Ann Neurol 72: 91-102.

Russo SJ, Dietz DM, Dumitriu D, Morrison JH, Malenka RC, Nestler EJ. 2010. The addicted synapse: mechanisms of synaptic and structural plasticity in nucleus accumbens. Trends Neurosci 33: 267-276.

Sabatini BL, Svoboda K. 2000. Analysis of calcium channels in single spines using optical fluctuation analysis. Nature 408: 589-593.

Schofield CM, Kleiman-Weiner M, Rudolph U, Huguenard JR. 2009. A gain in $\mathrm{GABA}_{\mathrm{A}}$ receptor synaptic strength in thalamus reduces oscillatory activity and absence seizures. Proc Natl Acad Sci 106: 7630-7635.

Setou M, Nakagawa T, Seog DH, Hirokawa N. 2000. Kinesin superfamily motor protein KIF17 and mLin-10 in NMDA receptor-containing vesicle transport. Science 288: 1796-1802.

Sheng Y, Zhang L, Su SC, Tsai L-H, Zhu JJ. 2015. Cdk5 is a new rapid synaptic homeostasis regulator capable of initiating the early Alzheimer-like pathology. Cereb Cortex doi: 10.1093/cercor/bhv032.

Simms BA, Zamponi GW. 2014. Neuronal voltage-gated calcium channels: structure, function, and dysfunction. Neuron 82: 24-45.

Smith SL, Smith IT, Branco T, Hausser M. 2013. Dendritic spikes enhance stimulus selectivity in cortical neurons in vivo. $\mathrm{Na}$ ture 503: 115-120.

Snead OC III. 1995. Basic mechanisms of generalized absence seizures. Ann Neurol 37: 146-157.

Steriade M. 2005. Sleep, epilepsy and thalamic reticular inhibitory neurons. Trends Neurosci 28: 317-324.

Stornetta RL, Zhu JJ. 2011. Ras and Rap signaling in synaptic plasticity and mental disorders. Neuroscientist 17: 54-78.

Talley EM, Cribbs LL, Lee JH, Daud A, Perez-Reyes E, Bayliss DA. 1999. Differential distribution of three members of a gene family encoding low voltage-activated (T-type) calcium channels. J Neurosci 19: 1895-1911.
Tenney JR, Glauser TA. 2013. The current state of absence epilepsy: can we have your attention? Epilepsy Curr 13: 135-140.

Tyvaert L, Chassagnon S, Sadikot A, LeVan P, Dubeau F, Gotman J. 2009. Thalamic nuclei activity in idiopathic generalized epilepsy: an EEG-fMRI study. Neurology 73: 2018-2022.

Udagawa T, Swanger SA, Takeuchi K, Kim JH, Nalavadi V, Shin J, Lorenz LJ, Zukin RS, Bassell GJ, Richter JD. 2012. Bidirectional control of mRNA translation and synaptic plasticity by the cytoplasmic polyadenylation complex. Mol Cell 47: 253-266.

Vitko I, Chen Y, Arias JM, Shen Y, Wu XR, Perez-Reyes E. 2005. Functional characterization and neuronal modeling of the effects of childhood absence epilepsy variants of $C A C N A 1 H$, a T-type calcium channel. J Neurosci 25: 4844-4855.

Wang G, Zhu JJ. 2014. DISC1 dynamically regulates synaptic Nmethyl-D-aspartate responses in excitatory neurons. Biol Psychiatry 75: 348-350.

Wang G, Wyskiel DR, Yang W, Wang Y, Milbern LC, Lalanne T, Jiang X, Shen Y, Sun Q-Q, Zhu JJ. 2015. An optogenetics- and imaging-assisted simultaneous multiple patch-clamp recordings system for decoding complex neural circuits. Nat Protoc 10: 397-412.

Wei J, Graziane NM, Wang H, Zhong P, Wang Q, Liu W, HayashiTakagi A, Korth C, Sawa A, Brandon NJ, et al. 2014. Regulation of N-methyl-D-aspartate receptors by disrupted-in-schizophrenia-1. Biol Psychiatry 75: 414-424.

Williams D. 1953. A study of thalamic and cortical rhythms in petit mal. Brain 76: 50-69.

Yao J, Davies LA, Howard JD, Adney SK, Welsby PJ, Howell N, Carey RM, Colbran RJ, Barrett PQ. 2006. Molecular basis for the modulation of native $\mathrm{T}$-type $\mathrm{Ca}^{2+}$ channels in vivo by $\mathrm{Ca}^{2+} /$ calmodulin-dependent protein kinase II. I Clin Invest 116: 2403-2412.

Yasuda R, Sabatini BL, Svoboda K. 2003. Plasticity of calcium channels in dendritic spines. Nat Neurosci 6: 948-955.

Zaman T, Lee K, Park C, Paydar A, Choi JH, Cheong E, Lee CJ, Shin HS. 2011. $\mathrm{Ca}_{\mathrm{V}} 2.3$ channels are critical for oscillatory burst discharges in the reticular thalamus and absence epilepsy. Neuron 70: 95-108.

Zhu JJ. 2009. Activity level-dependent synapse-specific AMPA receptor trafficking regulates transmission kinetics. J Neurosci 29: 6320-6335.

Zhu J,, Esteban JA, Hayashi Y, Malinow R. 2000. Postnatal synaptic potentiation: delivery of GluR4-containing AMPA receptors by spontaneous activity. Nat Neurosci 3: 1098-1106. 


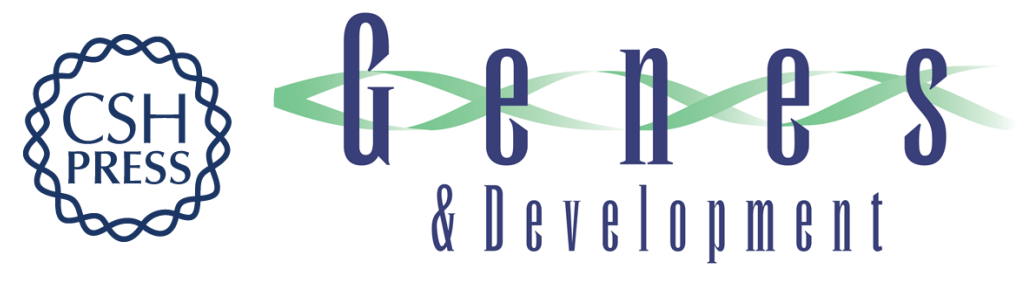

\section{Cay3.2 calcium channels control NMDA receptor-mediated transmission: a new mechanism for absence epilepsy}

Guangfu Wang, Genrieta Bochorishvili, Yucai Chen, et al.

Genes Dev. 2015, 29:

Access the most recent version at doi:10.1101/gad.260869.115

\section{Supplemental http://genesdev.cshlp.org/content/suppl/2015/07/28/29.14.1535.DC1 \\ Material}

References This article cites 79 articles, 22 of which can be accessed free at:

http://genesdev.cshlp.org/content/29/14/1535.full.html\#ref-list-1

Creative This article is distributed exclusively by Cold Spring Harbor Laboratory Press for the first

Commons six months after the full-issue publication date (see

License http://genesdev.cshlp.org/site/misc/terms.xhtml). After six months, it is available under a Creative Commons License (Attribution-NonCommercial 4.0 International), as described at http://creativecommons.org/licenses/by-nc/4.0/.

Email Alerting Receive free email alerts when new articles cite this article - sign up in the box at the top Service right corner of the article or click here.

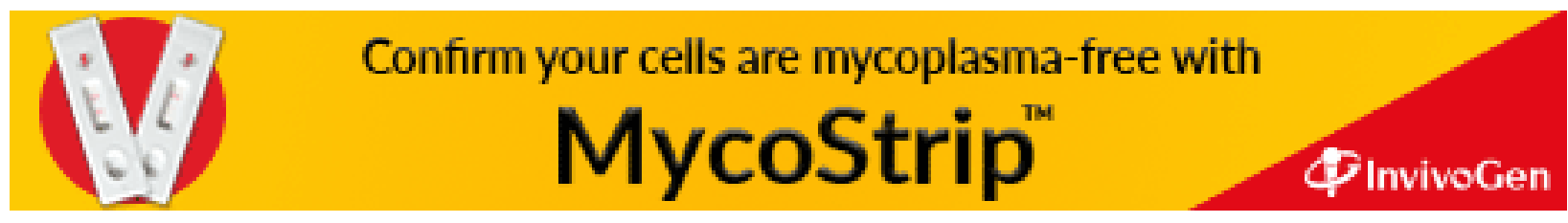

